\title{
Hybridization of MMT/Lignocellulosic Fiber Reinforced Polymer Nanocomposites for Structural Applications: A Review
}

\author{
Aisyah Humaira Alias ${ }^{1,2}{ }^{(0}$, Mohd Nurazzi Norizan $\left.{ }^{3}{ }^{(}\right)$, Fatimah Athiyah Sabaruddin ${ }^{4}(\mathbb{D}$,

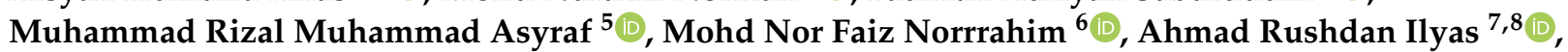 \\ Anton M. Kuzmin ${ }^{9}{ }^{\mathbb{D}}$, Marwah Rayung ${ }^{10}$, Siti Shazra Shazleen ${ }^{1}{ }^{\mathbb{D}}$, Asmawi Nazrin ${ }^{1}$, \\ Shah Faisal Khan Sherwani ${ }^{1}{ }^{\mathbb{D}}$, Muhammad Moklis Harussani ${ }^{1,2} \mathbb{D}^{\mathbb{D}}$, Mahamud Siti Nur Atikah ${ }^{11}$, \\ Mohamad Ridzwan Ishak ${ }^{4}$, Salit Mohd Sapuan ${ }^{1,2}$ and Abdan Khalina ${ }^{1, *}$
}

Citation: Alias, A.H.; Norizan, M.N. Sabaruddin, F.A.; Asyraf, M.R.M.; Norrrahim, M.N.F.; Ilyas, A.R.; Kuzmin, A.M.; Rayung, M. Shazleen, S.S.; Nazrin, A.; et al. Hybridization of MMT/Lignocellulosic Fiber Reinforced Polymer Nanocomposites for Structural Applications: A Review. Coatings 2021, 11, 1355. https:// doi.org/10.3390/coatings11111355

Academic Editor: Philippe Evon

Received: 27 September 2021

Accepted: 21 October 2021

Published: 3 November 2021

Publisher's Note: MDPI stays neutral with regard to jurisdictional claims in published maps and institutional affiliations.

Copyright: (C) 2021 by the authors Licensee MDPI, Basel, Switzerland. This article is an open access article distributed under the terms and conditions of the Creative Commons Attribution (CC BY) license (https:// creativecommons.org/licenses/by/ $4.0 /)$
1 Institute of Tropical Forestry and Forest Products (INTROP), Universiti Putra Malaysia (UPM), Seri Kembangan 43400, Malaysia; a.humaira.aisyah@gmail.com (A.H.A.); shazra.shazleen@yahoo.com (S.S.S.); nazrinnurariefmardi@gmail.com (A.N.); faisalsherwani786@gmail.com (S.F.K.S.); mmharussani17@gmail.com (M.M.H.); sapuan@upm.edu.my (S.M.S.)

2 Department of Mechanical and Manufacturing Engineering, Faculty of Engineering, Universiti Putra Malaysia (UPM), Seri Kembangan 43400, Malaysia

3 Centre for Defence Foundation Studies, Universiti Pertahanan Nasional Malaysia (UPNM), Kem Perdana Sungai Besi, Kuala Lumpur 57000, Malaysia; mohd.nurazzi@gmail.com

4 Faculty of Biotechnology and Biomolecular Sciences, Universiti Putra Malaysia (UPM), Seri Kembangan 43400, Malaysia; atiyah88@gmail.com (F.A.S.); mohdridzwan@upm.edu.my (M.R.I.)

5 Department of Aerospace Engineering, Universiti Putra Malaysia (UPM), Seri Kembangan 43400, Malaysia; asyrafriz96@gmail.com

6 Research Centre for Chemical Defence, Universiti Pertahanan Nasional Malaysia (UPNM), Kem Perdana, Sungai Besi, Kuala Lumpur 57000, Malaysia; faiznorrrahim@gmail.com

7 School of Chemical and Energy Engineering, Faculty of Engineering, Universiti Teknologi Malaysia (UTM), Skudai 81310, Malaysia; ahmadilyas@utm.my

8 Centre for Advanced Composite Materials (CACM), Universiti Teknologi Malaysia, UTM Johor Bahru, Skudai 81310, Malaysia

9 Department of Mechanization and Agricultural Products Processing, Ogarev Mordovia State University 430005 Saransk, Russia; kuzmin.a.m@yandex.ru

10 Faculty of Science, Universiti Putra Malaysia (UPM), Seri Kembangan 43400, Malaysia; marwahrayung@yahoo.com

11 Department of Chemical and Environmental Engineering, Universiti Putra Malaysia (UPM), Seri Kembangan 43400, Malaysia; sitinuratikah_asper7@yahoo.com

* Correspondence: khalina@upm.edu.my

Abstract: In the recent past, significant research effort has been dedicated to examining the usage of nanomaterials hybridized with lignocellulosic fibers as reinforcement in the fabrication of polymer nanocomposites. The introduction of nanoparticles like montmorillonite (MMT) nanoclay was found to increase the strength, modulus of elasticity and stiffness of composites and provide thermal stability. The resulting composite materials has figured prominently in research and development efforts devoted to nanocomposites and are often used as strengthening agents, especially for structural applications. The distinct properties of MMT, namely its hydrophilicity, as well as high strength, high aspect ratio and high modulus, aids in the dispersion of this inorganic crystalline layer in water-soluble polymers. The ability of MMT nanoclay to intercalate into the interlayer space of monomers and polymers is used, followed by the exfoliation of filler particles into monolayers of nanoscale particles. The present review article intends to provide a general overview of the features of the structure, chemical composition, and properties of MMT nanoclay and lignocellulosic fibers. Some of the techniques used for obtaining polymer nanocomposites based on lignocellulosic fibers and MMT nanoclay are described: (i) conventional, (ii) intercalation, (iii) melt intercalation, and (iv) in situ polymerization methods. This review also comprehensively discusses the mechanical, thermal, and flame retardancy properties of MMT-based polymer nanocomposites. The valuable properties of MMT nanoclay and lignocellulose fibers allow us to expand the possibilities of using polymer nanocomposites in various advanced industrial applications. 
Keywords: bamboo; kenaf; MMT; natural fiber; polymer composites

\section{Introduction}

At present, researchers are aware of the necessity of developing new composite products with high mechanical and thermal stability for structural applications. In the service life of power transmission, marine, automobile, and aerospace structures, several factors can cause damage to the structural integrity of polymer composite and reduce their lifespan due to high impact, creep, and fatigue loads from the external environment [1-4]. Furthermore, the potential for penetration and other such impacts can lead to extensive delamination, which results in degradation of the structural performance of composites [5-7]. For high-performance applications such as fire extinguishers, armored vehicles, and aircraft, the main purpose of the product is to have a high ratio of strength-to-weight structure [8]. Generally, thermoplastic composite materials exhibit high strength properties, which commonly decrease to a low value in terms of damping capacity due to its viscoelastic properties [9]. This leads to valuable properties for structural purposes.

Currently one can observe growing popularity and market demand for natural fiberreinforced polymer composites due to their advantages of low price, light weight and versatile applications $[10,11]$. However, lignocellulosic fibers such as sugar palm, kenaf, coir etc. exhibit low mechanical properties due to their hydrophilic properties and high moisture rate when used as reinforcement in polymer composites [12-14]. Moreover, the main drawback associated with the inclusion of lignocellulosic fiber in polymeric resin is the lack of surface adhesion between the two phases, which affects the flow properties of the final biocomposite laminate $[15,16]$.

The previously mentioned drawbacks of lignocellulosic fiber composites can be addressed either by regulating the fiber loading and orientation, fabric stacking sequence, fiber treatment as well as the use of nanofiller additives [17-20]. Several fiber treatment methods either via physical approaches such as plasma or corona treatment and steam explosion as well as gamma irradiation $[10,21]$ and chemical methods such as alkaline treatment, acetylation methods and coating techniques using hydrophobic polymers have been reported [22-26]. A significant decrease in water uptake of jute-reinforced polyester composites from the incorporation of synthetic fibers such as E-glass has also been discovered [27]. Research revealed that the inclusion of impermeable fillers along with lignocellulosic fiber inside polymer composites is one of the most significant approaches to lower the moisture uptake of composites. In this case, the filler factors such as filler concentration, distribution, shape and size would reflect on the water barrier, mechanical, and thermal properties of the final composites [28,29].

Heretofore, many studies and reviews have mentioned the superiority of reinforcement with smaller size particles which has great importance for the overall reinforcement effect in the matrix system [30,31]. An escalation of progress and interest can be seen in the application of plate-structured, nanofiller-filled materials represented by nanocomposites due to their high aspect ratio [32]. These nanofiller-filled materials, particularly when in particle sizes in the vicinity of $100 \mathrm{~nm}$ and below, have shown great effect in imparting a high degree of reinforcement. In fact, the reinforcement achieved by using $3-5 \%$ by weight of nano-scale reinforcement is similar to that achievable using $20-30 \%$ of a micro-scale filler. Therefore, the incorporation of nanofillers in composites systems is much more preferred due to their high specific interfacial area, which enables higher interfacial interactions, thus increasing the modulus properties of the final materials. In general, nanofillers are categorized based on their dimensions. Mrinal [31] has listed the types of nanofiller including one dimensional nanofillers such as nanotubes and nanowires, two dimensional ones like nanoclays and graphene, and three dimensional examples, for instance spherical and cubical nanoparticles. Carbonaceous nanofillers like nanotubes and graphene impart excellent properties that are attributed to their high mechanical strength and high aspect 
ratio, whilst, clays are naturally found as platelets, stacked from a few to as many as one thousand sheets. Montmorillonite (MMT), the most popular clay nanofiller, is comprised of two silicates layers of octahedral sheets of alumina that are sandwiched together. This aluminosilicate with low dimensions of $1-5 \mathrm{~nm}$ thickness and $100-500 \mathrm{~nm}$ in diameter will impart platelets with a high aspect ratio $(>50)$, hence providing stiffness and strength to the composite [33].

Presently, global demand for nanofillers like MMT clay and organically modified montmorillonite (OMMT) is growing due to the potential of using nanoparticles to' extensively modify the overall properties of polymer composites [34,35]. Nanoclay particles are composed of layered silicates. Examples of nanoclays are compounds such as pyrophyllite, organoclay, hectorite, saponite and nontronite nanoclay and MMT clay. Among these, MMT clay, which is the main constituent of bentonite, is the most regularly used layered silicate in polymer matrices due to its properties. MMT clay is well known as having a good filler anisotropy, high aspect ratio, excellent barrier properties, great strength and stiffness, as well as good thermal stability [36,37]. Despite the many promising advantages of MMT fillers in composites, the hydrophilicity of the nanoclay leads to difficulties in homogenously distributing it in the polymer matrix. Subsequently, this would induce disparity in the distribution of electrical fields in the material and inferior electrical performance of the resulting nanocomposites. Nanoclays can be commonly modified via ion exchange reactions to form organophilic species which allow the polymer molecules to penetrate between the clay galleries [38]. Besides that, the use of organic moieties as modifiers of MMT silicates can lead to a decrease in the polymer crosslinking, consequently inhibiting the interfacial adhesion between the polymer matrix and the nanofiller [36].

The combination of bio-based fibers/matrices with synthetic fibers/matrices through hybridization provides a novel approach for overcoming the drawbacks of solely natural fibers or matrices. By combining MMT nanoclay as a reinforcement agent into a composite's composition, it is possible to address some of the drawbacks of one type of reinforcement compared to another. Hybridization of MMT clay with lignocellulosic fibers could improve the thermal, mechanical and physical characteristics of biocomposites, allowing them to be used in a variety of applications [39].

As mentioned in the previous paragraphs, MMT can be used as an additive for the cross-arm structure in transmission towers since it significantly promotes good electrical resistance performance for composites while elevating the composites' mechanical performance $[38,40,41]$. To increase the number of potential applications, lignocellulosic composites' properties need to be more easy to modulate and flexible in terms of improvement to match the required performance of various applications [42-46]. In this manuscript, we narrow our survey to the methods of extraction, treatment and modification, classification, and applications of MMT fillers. This work aims to review the recent progress on the impact of MMT fillers hybridised with lignocellulosic fibers on the mechanical and thermal properties of reinforced polymer composites.

\section{MMT Nanoclay}

MMT is a member of the natural smectite group and is categorized as a phyllosilicate mineral with a nanolayered structure that has high biocompatibility and biodegradability as well as high mechanical characteristics [47]. Table 1 lists the most essential physical and chemical characteristics of MMT [48]. The common substituents for MMT particles are iron $(\mathrm{Fe})$, potassium $(\mathrm{K})$, aluminium and other cations, where their ratios may vary greatly according to their source [49]. The precise theoretical formulation of MMT, according to Uddin, [49], had never been found in Nature due to the charge imbalance introduced by the cation substitution. The chemical formula for MMT is shown in Equation (1):

$$
(\mathrm{Na}, \mathrm{Ca})_{0.33}(\mathrm{Al}, \mathrm{Mg})_{2}\left(\mathrm{Si}_{4} \mathrm{O}_{10}\right)(\mathrm{OH})_{2} \cdot n \mathrm{H}_{2} \mathrm{O}
$$

The molecular formula of MMT is $\mathrm{Al}_{2} \mathrm{H}_{2} \mathrm{O}_{12} \mathrm{Si}_{4}$ [49]. and aluminium oxides are present in the oxide composition, while calcium is the man mineral in MMT. The basic molecular 
structure is made up of silica tetrahedra and aluminium octahedral units. The $\mathrm{Si}^{+4}$ cation has fourfold tetrahedral coordination with oxygen, whereas the cation $\mathrm{Al}^{+3}$ has six-fold or octahedral coordination with oxygen [49].

Table 1. Physical and chemical characteristics of MMT.

\begin{tabular}{|c|c|}
\hline Properties & Description \\
\hline \multicolumn{2}{|c|}{ Physical properties } \\
\hline Color & White, grey, beige to buff \\
\hline Surface area $\left(\mathrm{m}^{2} / \mathrm{g}\right)$ & 240 \\
\hline Bulk density (g/L) & 370 \\
\hline Diameter of particles $(\mu \mathrm{m})$ & 1 \\
\hline Length of particles (nm) & $100-150$ \\
\hline Surface dimensions (nm) & $300-600$ \\
\hline Crystal system & Monoclinic \\
\hline Transparency & Translucent \\
\hline Fracture & Irregular \\
\hline Aspect ratio & High \\
\hline Nature & Hydrophilic \\
\hline \multicolumn{2}{|c|}{ Chemical properties } \\
\hline \multicolumn{2}{|c|}{ Chemical composition $(\%)$} \\
\hline $\mathrm{SiO}_{2}$ & 73.0 \\
\hline $\mathrm{Al}_{2} \mathrm{O}_{3}$ & 14.0 \\
\hline $\mathrm{Fe}_{2} \mathrm{O}_{3}$ & 2.7 \\
\hline $\mathrm{K}_{2} \mathrm{O}$ & 1.9 \\
\hline $\mathrm{MgO}$ & 1.1 \\
\hline $\mathrm{Na}_{2} \mathrm{O}$ & 0.6 \\
\hline $\mathrm{CaO}$ & 0.2 \\
\hline
\end{tabular}

MMT is comprised of two O-Si-O tetrahedral sheets of silica sandwiched by an alumina layer, O-Al(Mg)-O octahedral sheet, 2:1 clay [50]. Silica layers form a hexagonal network by sharing three corners with neighboring tetrahedra [50]. Each tetrahedron's remaining fourth corner connects to an adjacent octahedral sheet. Aluminium or magnesium, in six-fold coordination with oxygen from the tetrahedral layer and with hydroxyls, make up the octahedral sheets. To create the elementary particles of MMT, neighboring layers of approximately $10 \mu \mathrm{m}$-sized are stacked together assisted by van der Waals forces and electrostatic forces, or by hydrogen bonding [51]. As seen in Figure 1, the particles aggregate to produce micrometer-to millimeter-scale particles [52]. The layer structure of MMT may vary as a consequence of its changeable structure, allowing for the creation of a range of hybrids and composites [53]. Figure 1a shows a side view, where tetrahedral MMT units are assembled through weak van der Waals and electrostatic forces to form the primary particles, and Figure $1 \mathrm{~b}$ shows a top view of the hexagonal structure of the oxygen and hydroxyl ligands of the octahedral layer.

Physical and chemical approaches can be used to overcome the van der Waals forces and the electrostatic forces that stack the layers together [49]. According to Nakato and Miyamoto, MMT particles have plate-like shapes with surface dimensions of around 300 to $600 \mathrm{~nm}$ and a mean diameter of around $1 \mu \mathrm{m}$ [50]. Thus, MMT exhibits a large aspect ratio of around 50 to 1000 . In addition, MMT shows great hydrophilic nature where its water content tendency increases when exposed to water [54]. However, because polymers are typically organophilic, researchers have developed modified MMT forms by altering the clay surface. MMT may very well be made compatible with common petroleumbased polymers and distributed easily within the polymers for improved characteristics in nanocomposites after surface compatibilization or intercalation [50]. Due to these characteristics, MMT is the most common filler utilized in biocomposites and nanocomposite applications, in order to improve a particular property of materials [55-62]. 


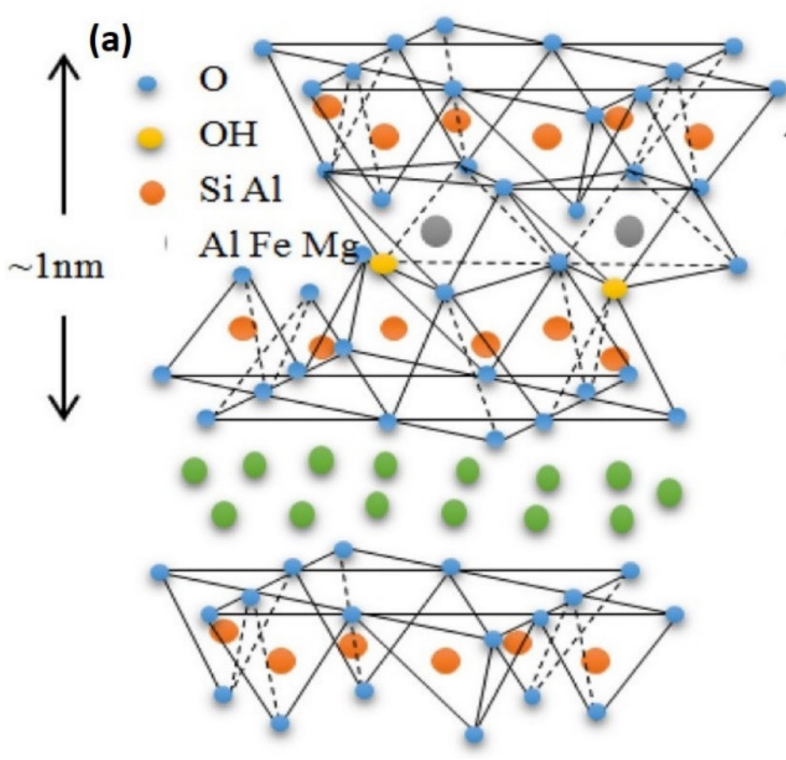

(b)

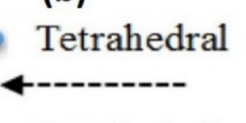

Figure 1. Schematic representation of the MMT structure. (a) Side view: tetrahedrons units of Mt assembled through weak van der Waals and electrostatic forces to form the primary particles, and (b) top view: hexagonal structure of oxygen and hydroxyl ligands of the octahedral layer. Reproduced from [63].

Due to the high aspect ratio and wide surface area of MMT nanolayers, it is extremely possible that the inclusion and dispersion of MMT nanolayers into the polymer matrix would result in MMT/polymer nanocomposites with significantly improved mechanical properties [52,64]. According to Zhu et al. [52], the addition and dispersion of MMT nanolayers into the polymer matrix results in MMT/polymer nanocomposites with significantly improved mechanical [65] and thermal properties [66,67], good oxygen and water barrier properties [68,69], as well as better flame retardancy [70]. As a result, intercalating MMT into nanolayers is critical for manufacturing effective MMT/polymer nanocomposites. Figure 2 shows the schematic diagram of in situ exfoliations of MMT to aid its intercalation into the polymer matrix. In situ exfoliation of MMT comprises the introduction of MMT to a liquid monomer or a monomer solution for it to expand and the monomer to reach the interlayer gap of MMT [52], called the polymerization process [71].

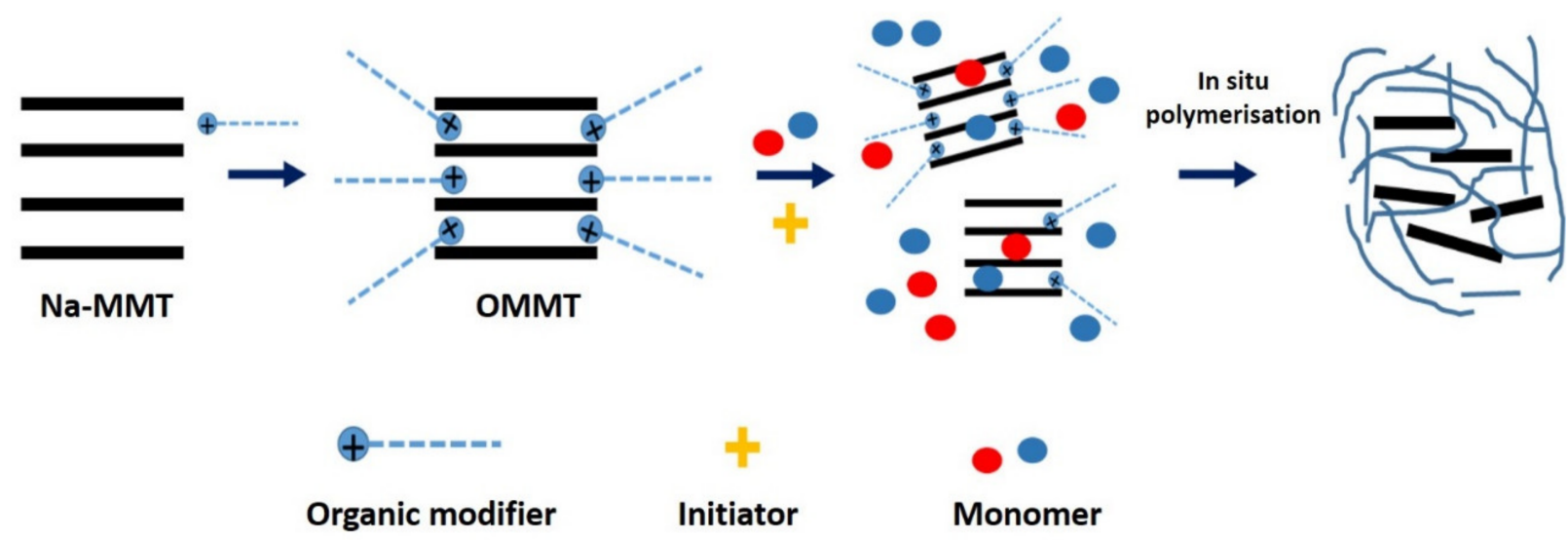

Figure 2. Schematic diagram of in situ exfoliation of MMT to aid its intercalation in polymer matrix. Reproduced from [72].

According to previous works, it was discovered that adding nanoclay and rice husk (RH) to high-density polyethylene (HDPE) improved its mechanical characteristics [73]. Nanoclay intercalation altered the crystallization behaviour of RH-filled HDPE by raising the crystallization temperature, enthalpy, and crystallinity. According to previous research, a combination of nanoclay and hemp has a synergistic impact on the flexibility and stiffness 
of PP [74]. With increasing nanoparticle concentration, there is a substantial reduction in water absorption and thickness swelling. The presence of nanoparticles improved dynamic mechanical behaviour, as well as fire retardancy and dimensional stability. Numerous studies have been done on the influence of nanoclays on the thermal stability of polymers such as polystyrene (PS) and ethylene vinyl acetate (EVA) [75]. The thermal stability of nanoclay-containing nanocomposites improved significantly as the nanoclay concentration increased. However, over a certain percentage of nanoclay (generally $5 \%$ ), the thermal stability either plateaus or begins to abruptly decrease. The degree of dispersion, like that of most nanocomposites, has a direct impact on the thermal stability of PS/nanoclay composite systems. Polymer chains entrapped between clay platelets were linked to a significant increase in thermal stability [75].

The production of polymer clay nanocomposites is now one of the most important uses of nanoclays. These natural nanomaterials can also be used as rheological modifiers and additives in paints, inks, greases, and cosmetics, as well as pollution control bio-systems carriers and medication delivery systems [76]. When a small amount of MMT is incorporated into the polymer matrix, the polymer is modified, resulting typically in a significant improvement in the physical, mechanical, fracture, wear resistance, thermal stability, peak heat release rate, flame retardancy, biocompatibility, and chemical properties of the resulting composite compared to standard materials [77-79]. MMT nanoclays and acid-treated MMT are also often employed in catalytic cracking, acid-based catalysis, and materials applications. Organoclays might be utilized as gas absorbents, rheological modifiers, polymer nanocomposites, and drug delivery carriers, among other applications [80].

\section{Lignocellulosic Fibers}

Lignocellulosic fiber is the scientific name that refers to natural fibers. All natural fibers contain a few constituents, which are cellulose, hemicelluloses, and lignin. These constituents are mainly attached by hydrogen bonds [81]. The mechanical and physical properties of lignocellulosic fibers are influenced by their chemical composition. Moreover, lignocellulosic fibers are hydrophilic due to the presence of an abundance of hydroxyl groups, thus they can absorb water [82]. Figure 3 (reproduced from [79]) shows the schematic structure of lignocellulosic fibers. The chemical constituents of lignocellulosic fibers depend on the geographic location where the plants are grown [83]. Fibers that contain more cellulose might have higher mechanical and good thermal properties [83], while a high hemicellulose content will promote fiber degradation at low temperatures and absorb more moisture [84-86]. Nevertheless, lignocellulosic fiber-containing natural materials are commonly obstinately resistant to any external attack due to their high crystallinity and the high degree of polymerization of cellulose, which are protected by the lignin constituents that lower the accessible surface area and impart high fiber strength. In addition, lignin also linked to both hemicellulose and cellulose, has a function of providing structural support, impermeability and resistance against microbial attack (chemical and biological hydrolysis) and oxidative stress [81]. 

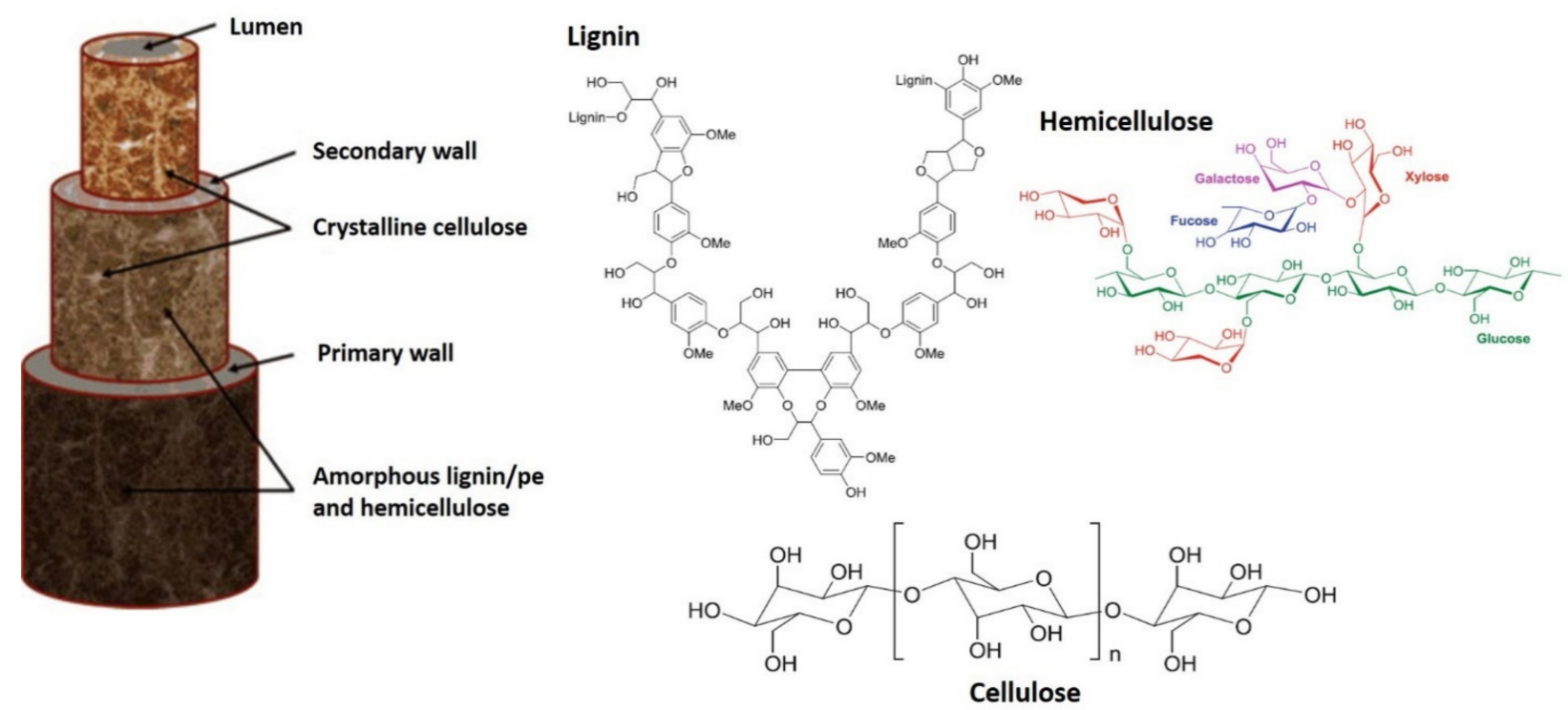

Figure 3. Schematic structure of lignocellulosic natural fiber. Reproduced from [84].

\subsection{Cellulose}

Cellulose is the primary component of lignocellulosic fibers [83]. Cellulose is made of long unbranched chains composed exclusively of glucose that are held together by hydrogen bonding. Cellulose fibrils have a particular cell geometry, which is a factor responsible for the properties of the fiber. The chemical formula of cellulose is $\left(\mathrm{C}_{6} \mathrm{H}_{10} \mathrm{O}_{5}\right)_{n}$ (where $\mathrm{n}$ represents the number of glucose groups). The overall structure of cellulose consists of crystalline and amorphous regions. Cellulose is composed of carbon (44.44\%), hydrogen $(6.17 \%)$, and oxygen $(49.39 \%)$ [85]. There are roughly 4000 to 8000 glucose molecules chained together. The polymer chain in cellulose is joined by glycosidic linkages at the $\mathrm{C} 1$ and C4 positions. Each repeating unit contains three hydroxyl groups. The presence of the hydroxyl group makes the cellulose hydrophilic. It is noted that these hydroxyl groups and their ability to form hydrogen bonds play a major role in directing the crystalline packing and also govern the physical properties of cellulose. The hydrogen bonding of many cellulose molecules to each other results in the formation of microfibers that can interact to form a fiber. Cellulose fibers usually have more than 500,000 cellulose molecules, therefore, cellulose fiber may contain 7000 to 15,000 glucose molecules per polymer [86]. The hydrogen bonding between cellulose fibrils is influenced by the mechanical properties of cellulose. Hydrogen bonding may not have the same strength as a covalent bond, however, the cumulative bonding energy of 2.5 billion hydrogen bonds is incredible. These properties, including its microcrystalline structure, make cellulose very difficult to dissolve or hydrolyze under natural conditions. In fact, the degree polymerization of cellulose also very high, in the range of 500 to 2500 , indicating the high thermal stability and mechanical properties of cellulose [87]. The biodegradation of cellulose also requires more enzymes due to its greater complexity compared to other constituents.

\subsection{Hemicellulose}

Hemicelluloses are polysaccharides that differ from cellulose in that they consist of several sugar moieties. These sugars include glucose and other monomers such as hexoses (galactose, mannose) and pentoses (xylose and arabinose). The structure of hemicellulose is mostly a branched carbohydrate (hexoses and pentoses) and has a low molecular weight [86]. It is strongly bound to cellulose fibrils by hydrogen bonding. It is partly soluble in water and hydroscopic because of its open structure, which contains hydroxyl and acetyl groups [88]. This characteristic also allows natural fibers to absorb significant amounts of water, making it a weaker polymer compared to cellulose. Moreover, hemicellulose 
also has an amorphous structure and a low degree of polymerization of 100 to 200, which suggests low mechanical properties and a low degradation temperature $[87,89]$.

\subsection{Lignin}

Lignin is a phenolic compound. Lignin is the second largest source of organic material in Nature [90]. It is a complicated amorphous polymer, hydrophobic in nature, formed of highly complex copolymers of aliphatic and aromatic constituents. Lignin contains hydroxyl, methoxyl and carbonyl groups [88,91]. The high carbon and low hydrogen content of lignin suggest that it is highly unsaturated or aromatic. The presence of hydroxyls and many polar groups in the lignin structure, resulting in strong intramolecular and intermolecular hydrogen bonds, making lignin essentially insoluble in any solvent. Phenolic hydroxyl and carboxyl groups allow lignin to be dissolved in alkaline solutions. Lignin binds the elementary fibers together with hemicellulose as cementing elements. Lignin imparts rigidity to the cell walls and fills the space between hemicellulose and cellulose [92]. Due to its hydrophobic character, lignin acts as a sealant to water, protection against biological attack and a stiffener to the fibers [93,94] Besides that, lignin can also be a compatibiliser between hydrophilic fibers and hydrophobic polymers, resulting in a stronger fiber-matrix interface [95]. In terms of degradation, lignin is degraded via oxidative process attributed to the secondary metabolism or to restricted availability of carbon, nitrogen, or sulphur which are commonly degraded as sole carbon, and energy sources [96], whilst in Nature, lignin is biodegraded by some white rot fungi, for instance from the basidiomycetes class, that degrade lignin more rapidly and extensively compared than other microorganisms. The white-rot fungi species, for example Ceriporiopsis subvermispora, Phellinus pini, Phlebia sp., Pleurotus sp., Phanerochaete chrysosporium etc. attack lignin more readily than cellulose and hemicellulose. In addition, these fungi also produce a set of ligninolytic enzymes that catalyze the oxidation of an array of aromatic substrates, producing aromatic radicals and changing the structure of the lignocellulose-containing raw materials and lignin [81].

Table 2 shows different lignocellulosic compositions for several natural fibers [97]. Generally, the cellulose, hemicellulose, and lignin in a typical lignocellulosic fiber fall within the range of $30 \%$ to $60 \%, 20 \%$ to $40 \%$, and $15 \%$ to $25 \%$, respectively. These lignocellulosic compositions greatly influence the mechanical properties of the fibers and result in significant improvements in the mechanical and thermal performance of polymer nanocomposites.

Table 2. Chemical composition of lignocellulosic fibers.

\begin{tabular}{ccccc}
\hline Natural Fiber & Cellulose & $\begin{array}{c}\text { Lignocellulosic Components (\%) } \\
\text { Hemicellulose }\end{array}$ & Lignin & Ref. \\
\hline Sugar Palm & 43.88 & 7.24 & 33.24 & {$[98]$} \\
Bagasse & 32 to 34 & 19 to 24 & 25 to 32 & {$[99]$} \\
Bamboo & 73.83 & 12.49 & 10.15 & {$[100]$} \\
Flax & 60 to 81 & 14 to 20.6 & 2.2 to 5 & \\
Hemp & 70 to 92 & 18 to 22 & 3 to 5 & \\
Jute & 51 to 84 & 12 to 20 & 5 to 13 & {$[101]$} \\
Kenaf & 44 to 87 & 22 & 15 to 19 & \\
Ramie & 68 to 76 & 13 to 15 & 0.6 to 1 & {$[102]$} \\
Sisal & 65.8 & 12 & 4.9 & {$[103]$} \\
Pineapple & 66.2 & 19.5 & 40 to 45 & {$[104]$} \\
Coir & 32 to 43 & 0.15 to 0.25 & & \\
\hline
\end{tabular}

\section{Processing Techniques for MMT/Natural Fiber Reinforced Polymer Nanocomposites}

Today, the advancements in nanotechnology have propelled the utilization of clay minerals as effective fillers and additives in polymers for desired applications. The reinforcement effect can produce significant improvements in polymers at very low filler contents of less than $5 \mathrm{wt} . \%$, compared to those achieved using traditional micro-size 
fillers ( $\geq 20$ wt.\%). However, natural sodium montmorillonite (NaMMT) must be surface modified to become OMMT for easier dispersion in the polymer matrix. The intercalation structure of poly(butylene) succinate (PBS)-reinforced OMMT and polylactic acid (PLA)-reinforced OMMT was observed and attributed to the strong interaction of hydroxyl groups in the clay structures with the carboxyl groups of the polyester. Meanwhile, the addition of NaMMT led to intercalation of TPS in the clay. MMT introduced in natural fiber reinforced polymer composites promotes resistance against chemical, heat, electricity, fire and UV light exposure [51].

There are some commonly utilized methods for incorporating nanoclays into polymer nanocomposites, such as intercalation of polymers, in-situ intercalative polymerization, and melt intercalation [105]. The mixing of clays, natural fibers and matrix generally applies three mixing techniques, namely mechanical mixing, magnetic stirring and sonication. Depending on the mixing technique used, the dispersion of nanoclays within the matrix can take the form of a phase-separated, intercalated or exfoliated nanocomposite structures. The most desired exfoliated structures present a complete separation of nanoclays due to the segregation of electrostatic forces between clay platelets by the polymer chain in the composites. Meanwhile, phase-separated structures indicate that the electrostatic forces between clay platelets cannot be overcome completely. This kind of structure is unfavorable to the properties of the nanocomposites as higher loading will be required for significant improvement, which otherwise can be achieved at lower loading for exfoliated and intercalated structures. An intercalated structure is formed when extended polymer chains are intercalated into the clay interlayers with the clay platelets still intact.

\subsection{Conventional Composite Fabrication Techniques for Nanocomposites}

Conventional techniques for fabricating composites, such as two-roll mill, twin-screw extruder, solution casting, compression and injection molding involve different clay incorporating techniques. Generally, twin-screw extruders and two-roll mills are the mixing machines used. The twin-screw extruder machine is a closed barrel containing two rotating screws mounted on splined shafts, which applies the melt intercalation technique utilizing the shear strength of mechanical mixing and high temperatures to mix clays and natural fibers into the matrix. The electrostatic binding force that clumped clay platelets together is broken down by the centrifugal force of rotating extruders in a high-pressure environment. Several studies [106,107] have shown that the equal channel angular extrusion (ECAE) method is able to re-engineer the nanofiller aspect ratio and orientation along with the crystalline lamellar structure. Polymer nanocomposite bars are extruded into a device made up of several pairs of channels of the same diameter, which intersect at the adjusted angles. Pairs of oblique channels within the plane can be rotated through the vertical axis to arrange different routes of deformation. Depending on the processing routes, nanoclays with shortened, closely packed, well-aligned and crystalline lamellae were compressed and diagonally well-oriented [108]. The two-roll mill consists of two rolls operating at different speeds that disentangle the clay particles and increase the clay galleries that enable the matrix to enter. Meanwhile, the solution casting method generally consists of three stages, including the dispersion of clay in a polymer solution, controlled removal of the solvent, and lastly composite film casting [109]. This solvent-based process involves mixing a polymer and prepolymer, which are soluble, and causing swelling of the clays layers [110]. The layered clays are then exfoliated using a solvent such as water, chloroform, or toluene. As the polymer/prepolymer are mixed with layered clays in a solution, the polymer chains intercalate and displace the solvent within the interlayers of the clay [109]. The solvent is then removed via vaporization or precipitation, and thus the intercalated sheets tend to reassemble and consequently form polymer/nanoclay composites. The dispersion of clay and natural fibers is usually done through sonication and magnetic stirring. Magnetic stirring uses magnetic force to break the electrostatic force between clay platelets. Sonication applies sound waves to agitate the particles in solution. In the case of high viscosity materials such as epoxy resins, high sonication amplitude is required to 
agitate the clays within the matrix before applying auxiliary natural fiber reinforcements. Meanwhile, compression and injection molding usually use premixed materials through intercalation of polymer and melt intercalation to optimize the dispersion of fillers within the matrices. As the name suggested, compression molding applies compressive strength to fabricate a specimen using male and female molds. First, materials are placed into the female mold to be melted down before applying compressive force joining both molds to distribute the desired amount of resin throughout the designed mold. The joined molds are then compressed again at lower temperature to solidify the resin. For injection molding, premixed materials are filled into a heated barrel, mixed and then injected into a designed mold. As the materials cool off, they will harden into the form of the mold cavity.

\subsection{Intercalation of Polymer}

Polymer intercalation techniques disperse MMT in a solution in which the polymer has been dissolved. In this form, the stacked clay layers can be easily dispersed in an adequate solvent. The polymer can then enter into the clay galleries and establish an ordered multilayer structure when the solvent is removed. Ayana et al. [111] added NaMMT during starch gelatinization with the addition of a glycerol later melt intercalated with polylactic acid (PLA), producing TPS/PLA/NaMMT (60/40, w/w) nanocomposites. The exfoliation of NaMMT in the thermoplastic starch (TPS) acts as a compatibiliser by reducing the size distribution of the PLA in the TPS matrix. The average diameter of the dispersed domain (Dn) value of the TPS/PLA blend was recorded at $21.3 \mu \mathrm{m}$, whereas the incorporation of $0.5 \mathrm{phr}$ and $1.0 \mathrm{phr}$ of NaMMT into TPS/PLA showed Dn values of $17.2 \mu \mathrm{m}$ and 13.45 $\mu \mathrm{m}$, respectively. The complete exfoliation of NaMMT was due to the initial preparation of clay dispersion in a starch suspension. The delayed insertion of plasticizer facilitates the penetration of starch molecules into the clay galleries, leading to complete exfoliation. Tian et al. [112] prepared MMT-reinforced PVA/starch (50:50) nanocomposites using an intercalation polymer method for better clay dispersion. TEM analysis showed that after incorporation of $5 \%$ MMT the clay nanolayers were well dispersed at random within the matrix, indicating a highly exfoliated structure. At 10\% of MMT, poly(vinyl) alcohol (PVA) and starch macromolecules penetrated into the clay galleries and enlarged the spacing of clay nanolayers, forming intercalating structures. Through a similar method, Trifol et al. [113] reported that the reinforcement of 1\% of OMMT and 1\% of nanocellulose in PLA nanocomposites was sufficient to achieve a significant reduction of $57 \%$ in the water vapor permeability rate (WVTR) and 74\% in the oxygen vapor permeability rate, whilst preserving good transparency, thermal stability and decent mechanical properties compared to neat PLA. In this work it seemed that the two types of nanofillers had a synergistic effect, whereby the fibrous nanocellulose and nanoclay platelets formed a strong percolated network maintaining the integrity of the nanocomposite films. TEM analysis indicated a highly exfoliated structure for low clay loading films $(1 \%)$ while a higher clay loading $(3 \%)$ showed an exfoliated and small proportion of intercalated nanoclay structures. Meanwhile, even higher nanocellulose loading films (5\%) displayed a homogenous structure with no nanocellulose aggregates. Li et al. [114] firstly dispersed cellulose nanofibers (CNF) and NaMMT in an aqueous system, which was later mixed into corn starch CS) solution to obtain CS/NaMMT/CNF nanocomposite films through the solution casting method. CNF was observed to be distributed uniformly around or inserted into the lamella, indicating a good interaction between CNF and NaMMT. CNF bonded with starch by hydrogen bonds enters into the clay structures and enlarges the interlayer distance of NaMMT, thus forming ternary nanocomposites with a layered structure. At 3\% of NaMMT, the addition of CNF up to 7\% decreased the interlayer distance of NaMMT caused by the aggregation of CNF. Significant increments in mechanical properties and transparency values were recorded for the nanocomposite films with CNF loadings of up to 5\% only. At a higher CNF content, the number of active CNF sites was unable to interact with CS and NaMMT, thus allowing a weak stress transfer between the reinforcements and matrix. The in-situ polymerization method synthesizes polymer nanocomposites by using monomers, where 
the low molecular weight monomer can easily diffuse into the clay galleries, forming either an intercalated or an exfoliated structure.

\subsection{Melt Intercalation}

The melt intercalation or melt mixing method provides better mixing of the nanoclay fillers and polymers that are typically used on a mass production scale through extrusion and injection molding. The processing parameters such as rotor speed, temperature profile, feed rate, mixing period, melting conditions, die pressure, materials grade and content as well as the chemical composition of the nanoclay filler and polymer are important to synthesize composites with desirable properties [109]. The melt intercalation approach involves melting the polymer at a high temperature and then the filler is blended with the polymer at a high temperature under shear. This method requires MMT to be surface-modified to weaken the electrostatic forces holding the platelets together. Boonprasith et al. [115] used NaMMT and OMMT to reinforce TPS/PBS blended nanocomposites through a melt intercalation technique. The polarity of NaMMT does not have good affinity with PBS/TPS as compared to OMMT. OMMT is compatible with PBS, forming a strong interaction between the hydroxyl groups in OMMT and the carboxylic groups of PBS. Owing to this, the higher content of PBS in TPS/PBS (25:75) blended nanocomposites ensured the majority of the clay was well dispersed within the PBS phase during the mixing process. Meanwhile, NaMMT was suspected to reside within the TPS dispersed phase of higher content of TPS in TPS/PBS (75:25) blended nanocomposites. NaMMT is known to be more hydrophilic than OMMT. The extra moisture within NaMMT promoted starch gelatinization, which led to better interfacial interaction and effective heat transfer between the clay and the TPS dispersed phase. Higher WVTR and OTR were shown by PBS/TPS/OMMT owing to the tortuous structure formed by the exfoliation and intercalation of clay.

Zahedi et al. [116] prepared polypropylene (PP)/walnut shell flour (WSF)/OMMT (50:43:3) nanocomposites directly mixed using a twin-screw extruder with maleated anhydride grafted polypropylene (MAPP) (4\%) as a compatibiliser. SEM and TEM analysis for $3 \%$ of OMMT demonstrated a higher order of intercalation and good dispersion of clay layers in the nanocomposites as compared to 5\% of OMMT. The well-dispersed clay layers within nanocomposites promoted the mechanical properties of the composite due to the high stiffness of clay platelets and lower percolation points. At 5\%, OMMT was observed to agglomerate, which led to lower mechanical properties. Water absorption and thickness swelling rates decreased as the content of OMMT and MAPP increased. The dispersion of clay-filled up microvoids and fibers cavities creating a tortuous path preventing deeper water penetration through capillary action. Zhao et al. [117] investigated the relationship of untreated wood flour and silane-treated (WF) with OMMT in PVC-based composites through dry mixing using a high-speed mixer. TEM analysis showed that $0.5 \%$ of OMMT was homogenously dispersed as partially exfoliated structures in PVC/treated WF (100:70) composites. OMMT has better interfacial compatibility with treated WF resulting in a significant increase in impact strength and tensile strength (by 14.8\% and 18.5\%, respectively). The hydrophobic PVC and hydrophilic untreated WF displayed poor interfacial adhesion thus further incorporation of OMMT worsened the compatibility and increased the stress concentration points. At $3 \mathrm{wt}$. \% of OMMT content, the size of dispersed clays became larger and in part aggregated, which led to a minor reduction in the impact strength.

\subsection{In Situ Polymerization}

The high surface energy of the clay platelets induces the penetration of monomer molecules into the clay interlayer spacing to establish an equilibrium state. As polymerization occurs, the interlayer spacing of clay platelets increases and separates the clay platelets into a disoriented state resulting in an exfoliated structure. The polymerization can be initiated by exposure to heat or radiation and incorporation of catalyst or initiator via ion-exchange reactions. It seems that the surface modification of MMT and natural fibers are essential to establish good compatibility between fillers and hydrophobic polymers. 
Since MMT and natural fibers are rich in hydroxyl groups, they form strong hydrogen bonds with hydrophilic polymers such as TPS and PVA.

\section{Mechanical Properties of MMT/Natural Fiber Reinforced Polymer Nanocomposites}

Composites sample are subjected to mechanical evaluation to investigate the negative or positive hybrid effect of the composites. The common mechanical properties evaluated include Young's modulus, tensile strength, strain at yield, and shear stress, supported with morphological and rheological properties [118]. The hybridization of natural fibers and nanoclay fillers in the same type of matrix polymer has been the focus of researchers due to their easy availability, low density and low cost as well as their enhanced physical and mechanical properties [119]. The hybridizing technique between these two types of fillernatural fibers and nanoclay fillers-enables the reduction of some of the drawbacks of composite materials including low durability and low resistance to water absorption which make them incompatible with non-polar matrices [120]. It is expected that the modulus properties of hybrid composites will increase with the addition of a nanoclay filler loading due to its rigid properties, whilst natural fibers possess a high elastic modulus compared to that of the polymer matrix. Therefore, the addition of rigid filler like nanoclays to natural fiber-reinforced polymer composites enable improvement of the stiffness and strength which cannot be provided by the addition of natural fibers alone $[35,120]$. This occurrence is attributed to the action of the filler to fill the polymer voids and restrict the movement of polymer chains. This restriction then enhances the mechanical strength and rigidity, improving the load transfer at the matrix-fiber interface, reducing the gas and moisture penetration and improving the flammability properties [121,122].

Despite the enhanced properties provided by hybrid composites, the hydrophilic character of natural fibers and clay-based reinforcement fillers that causes poor interfacial adhesion creates difficulties in providing homogenous dispersions of filler in the composite system. Other than natural fibers, clay-based fillers are also known to have hydrophilic properties. Clays display interlayer formation where van der Waals gaps are created that normally present ions of alkali metals including $\mathrm{Na}+$ and $\mathrm{K}+$, or alkaline-earth ones like $\mathrm{Ca}^{2+}$. These counterbalance the negatively charged platelets and causes more water particles to be chemically linked and attached within the clay structure. Therefore, to improve the affinity between filler and the matrix, the inorganic cations are generally exchanged by ammonium and phosphonium cations. The resulting clays are referred to as organo-modified layered silicates (OMLS) and, in the case of MMT) [122,123]. As reported by Rozman et al. [124], the introduction of nanoclay filler in natural fiber-based composites at levels as low as $1 \mathrm{wt} . \%$ is likely to offer better stress transfer throughout the matrix which leads to improved impact and flexural properties. Similar findings by Hetzer and Dee [125] showed that with the addition of 3 to $5 \mathrm{wt}$. $\%$, nanoclay results in $30 \%$ better properties compared to conventional fillers.

However, the potential of agglomeration of filler can lead to deterioration of the composites, particularly at higher levels of nanoclay filler addition. Furthermore, the agglomeration of the filler also can lead to unstable stress concentrations and poor interfacial adhesion between natural fibers and polymers, which cause the brittleness of the composites [126]. Therefore, it is necessary to modify the surface of the fillers and utilize a compatibiliser to ensure their better dispersion and good adhesion with the polymer matrix [32,39,121]. For example, Majeed et al. [32] showed the potential of MMT in polypropylene $\mathrm{PP} / \mathrm{RH}$ composites as a water-resistant strengthening filler. By integrating MMT into the PP/RH system, the mechanical characteristics were improved and the reinforcement effect due to the application of the compatibilizing agent was notable. With the addition of RH and MMT into a polypropylene matrix, the tensile and flexural modulus improved by $63 \%$ and $92 \%$, which showed that higher stress was required for deformation as both RH and MMT are rigid and high-modulus materials. When MMT and PP-g-MAH were employed for the development of PP/RH-based nanocomposites, improved modulus values were achieved. The PP/RH composite tensile and flexural modulus rose by $5 \%$ 
and $4 \%$, by the addition of PP-g MAH and when MMT was used in the presence of the compatibilisers, it rose by $36 \%$ and $25 \%$, respectively. The enhancement in the modulus by the addition of the MMT in the composite can be attributed to the presence of delaminated, stiffer platelets and the high aspect ratio of the MMT in the PP polymer matrix, leading to increased interactions between PP chains.

Zahedi et al. [127] addressed the effects of OMMT as a reinforcing agent on the mechanical properties of almond shell flour-polypropylene bio-nanocomposites. Maleic anhydride grafted polypropylene (MAPP) was applied as a coupling agent to improve the poor interface between the lignocellulosic material (hydrophilic) and the polypropylene matrix (hydrophobic). The tensile and flexural properties attained their maximum values when 3 wt.\% OMMT was added. The increased population of OMMT molecules leads to agglomeration at a high degree of OMMT loading (5 wt.\%). Flexural strength and modulus improved as the OMMT loading was increased by up to 3\%. After 3\% MMT, it started decreasing. A greater stiffness of clay platelets and lower percolation points can be attributed to this $3 \mathrm{wt}$ \% OMMT load, which is the cause of the improved mechanical properties. This is due to the high aspect ratios of organo-clays and the high surface area of silicate polymer matrix layers, which lead to increased interactions between nano-scaled clay particles and the PP matrix, with good interfacial adhesion. The finding is evidenced in Figure 4 through SEM images of fracture surface of composites with and without addition of OMMT.
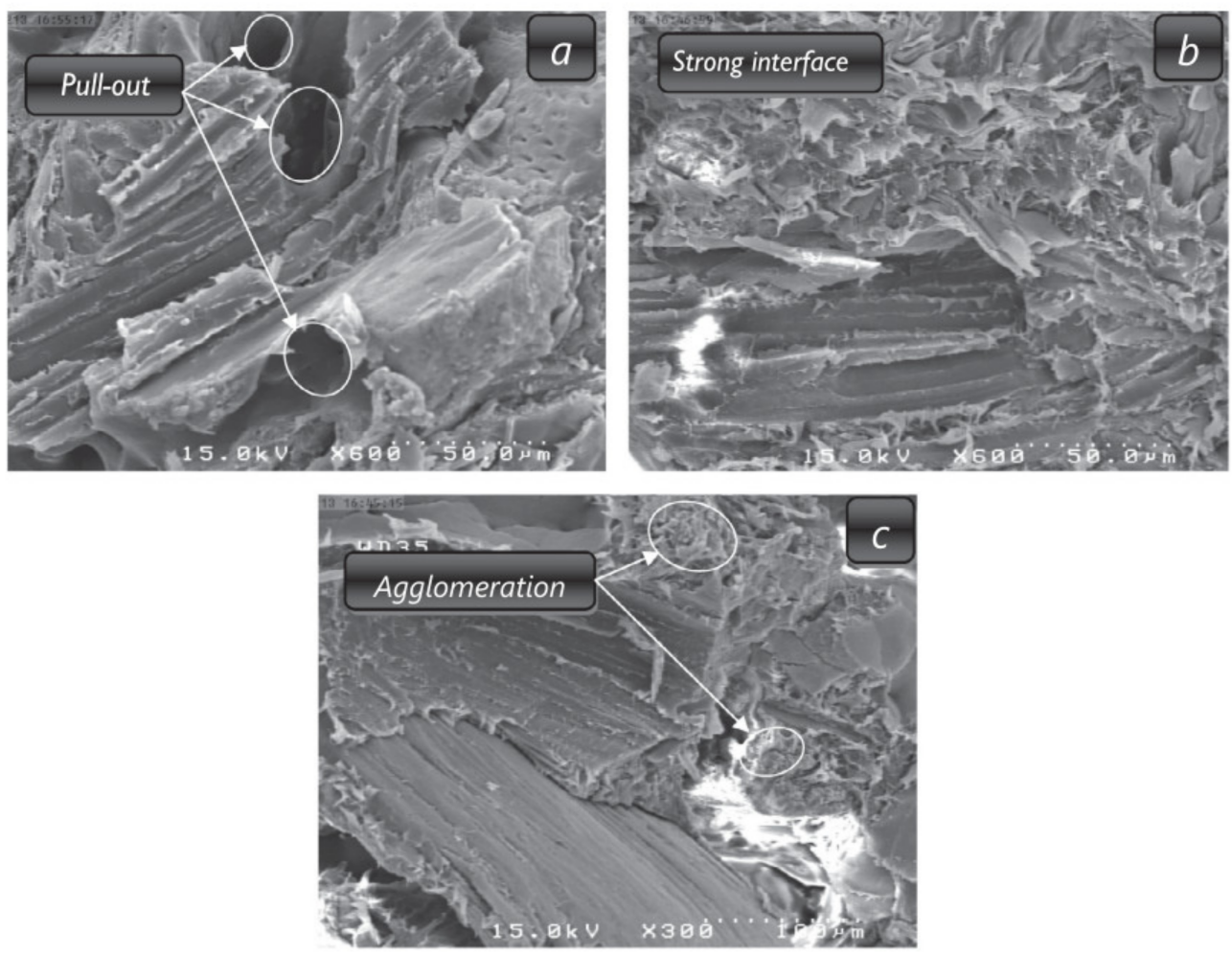

Figure 4. The SEM micrographs of fractured surfaces of composites types: (a) ASF/PP/MAPP composites, (b) ASF/PP/MAPP reinforced 3\% OMMT and (c) ASF/PP/MAPP reinforced 5\% OMMT. (ASF: Almond shell flour; PP: Polypropylene; MAPP: Maleic anhydride polypropylene; OMMT: organo-modified montmorillonite) [127].

Other than synthetic polymers, MMT also was utilized as a material for reinforcement in biopolymer-based composites. To date, to reduce the utilization of petroleum-based polymers, natural-based polymers known as biopolymers have become popular. Among all biopolymers, polylactic acid (PLA) has caught the attention of researchers due to its biodegradability, good processability and excellent biocompatibility properties. To enhance its properties, natural fibers and nanoclay fillers have been introduced into the system to 
develop cost-effective materials with superior properties compared to composites with carbon and glass fiber inclusion [34]. For example, Petersson and Oksman [128] have reported the effect of MMT and cellulose nanowhiskers (CNW) on PLA. Both tensile modulus and yield strength were increased with MMT, whereas the yield strength was increased by CNW. They had also found a higher ductility for PLA/CNW nanocomposites than for MMT/PLA nanocomposites.

The addition of MMT improved the tensile strength of PLA/MMT nanocomposite to reach a plateau of $5 \mathrm{phr}$ filler content and thereafter it declined at a higher level [129]. Compared to PLA/MMT nanocomposites, neat PLA displayed 63\% less tensile strength. This may be due to a significant reinforcing effect of the inorganic phase. The MMT filler is regularly distributed in the PLA and, therefore, sufficient percolation networks are established. An amount of $5 \mathrm{phr}$ of filler was appropriate for the MMT filler to achieve a maximum tensile strength. In excess of $5 \mathrm{phr}$, the tensile strength value declined. This was because of filler aggregation that resulted in stress concentration spots conducive to fractures. However, with increased MMT filler content, the Young's modulus of the PLA/MMT nanocomposite increased steeply. It was worth noting that, compared to pure PLA film, the Young's modulus of PLA/MMT nanocomposites was increased by $18 \%$. This increase was due to the rigid filling of MMT that restricts the movement of the segments in the polymer matrix [129].

It is observed that the tensile strength improves with the addition of CNW and reaches its maximum tensile strength at $3 \mathrm{phr}$, and then decreases with a higher filler content [129]. The tensile strength of an increase in the interaction between the filler and the matrix, thereby increasing the tensile strength. However, when the filler content is more than $3 \mathrm{phr}$, the tensile strength decreases. This reduction may be due to the accumulation of CNW in PLA, which then acts as a stress concentration point. However, the Young's modulus of PLA/CNW nanocomposites gradually increases with increasing CNW filler content. Compared to pure PLA, the Young's modulus of PLA/CNW nanocomposites is increased by $25 \%$. This increase is attributed to the hardening effect of the high modulus CNW reinforcing material [129]. The tensile, flexural, and impact properties of PLA-hybrid biocomposites were improved by $5.72 \%, 6.08 \%$, and $10.43 \%$ than PLA biocomposites, after adding $1 \mathrm{wt} . \%$ MMT [39].

Jalalvandi et al. [130], reported the effect of MMT nanoclay on mechanical properties of starch/PLA hybrid composites, indicated that the tensile strength, tensile modulus, and elongation at break increased after the addition of MMT clay. The tensile modulus values increase up to the MMT content of $4 \mathrm{phr}$. The MMT particles agglomerated over $4 \mathrm{phr}$ and consequently reduced the tensile modulus. The sample contains $4 \mathrm{phr}$ MMT of the highest Young's modulus observed. The Young's modulus of samples started to decrease with the further increase of MMT content in samples. The MMT particles had been unevenly spread across the PLA matrix when MMT content increased beyond $4 \mathrm{phr}$ and there was a chance of agglomerating MMT particles. For the tensile strength graph, with $2 \mathrm{phr}$ MMT loading, the tensile strength sample increased. Due to the exfoliated structure of the MMT-PLA/starch matrix, a significant rise in tensile values was considered. But after the MMT content was increased to $4 \mathrm{phr}$, there were no substantial changes. The tensile strength of $67 \mathrm{MPa}$ was further increased by the MMT loads. Surprisingly, very slight changes in the tensile strength at $68 \mathrm{MPa}$ were detected with the greatest MMT concentration, that is, $8 \mathrm{phr}$ [130].

Saba et al. [131] worked on mechanical properties of oil palm empty fruit bunch (OPEFB) nanofiller/kenaf fiber/epoxy-hybrid nanocomposites and reported that the tensile strength of nano OPEFB filler/kenaf/epoxy hybrid nanocomposites improved by $24.9 \%$ with kenaf/epoxy composites, whereas 20.7\% with MMT/kenaf/epoxy hybrid nanocomposites. By adding 3\% OMMT to kenaf/epoxy its tensile strength improved by $29.3 \%$ with respect to MMT/kenaf/epoxy hybrid nanocomposites whereas a $56 \%$ increment was observed as compared to nano-OPEFB/kenaf/epoxy hybrid nanocomposites. This is because of the strong reinforcing effects, a high aspect ratio, good interlayer spacing, and the OMMT 
platelet structure. This allows the stress concentration to be reduced efficiently under the action of tensile loads on the nanocomposites. In contrast, MMT is a soft and hydrophilic substance that makes it incompatible with the hydrophobic epoxy polymer matrix, which results in a comparatively low tensile strength with the kenaf hybrid nanocomposites filled by OMMT. Consequently, there was no strong interphase between the epoxy matrix and the dispersion phase, which reduces the applied concentrations of tensile stress, in contrast to nano OPEFB filler/kenaf/epoxy hybrid nanocomposites. It was also noted, with regard to the MMT/kenaf/epoxy hybrid nanocomposites, that OMMT hybrid nanocomposites show the highest tensile modulus, which is raised by $14 \%$. Good stiffening and clay layers' rigidity properties were the root cause of the improvement in tensile modulus of nanoclay (OMMT, MMT)-based kenaf hybrid nanocomposites than OPEFB-based kenaf hybrid nanocomposites. Similarly, the impact strength of OMMT/kenaf/epoxy hybrid nanocomposites improved by $25.9 \%$ as compared to MMT/kenaf/epoxy hybrid nanocomposites [131]. The combination of a nano filler and micro-size reinforcements in the polymer may be used to create stronger and lighter hybrid composites with improved mechanical characteristics for a range of housing and bridge applications.

In separate studies, instead of hybridizing the polymer composites using two types of fibers, the utilization of more types of fibers might impart better mechanical properties on the composite systems. In spite of being renewable, non-abrasive and low in cost, natural fiber hybrid composites also exhibit excellent mechanical properties and are environmentally friendly, which make them a material of choice for engineering markets, including the automotive and construction industries [132]. Besides, to complement current trends, the application of nanofillers like MMT nanoclay was also introduced into natural fibers hybrid composites to achieve advanced performance features suitable for future engineering applications. The hybridization of natural fiber reinforced polymer nanocomposites with nanoclay was studied by [133] using two types of natural fibers, viz. wood and coir fibers. The mechanical properties of the hybrid composites were found to be enhanced after the addition of MMT. The Fourier transform infrared spectra also proved the interaction between fiber, polymer and MMT by a new peak around $470 \mathrm{~cm}^{-1}$. The tensile properties of the hybrid of coir fiber/wood polymer composites with the addition of MMT showed the highest value compared to the hybrid composites without MMT addition. This finding supports the surface morphology properties as the hybrid composite with MMT loading showed a smoother surface and indicated high interfacial adhesion attributed to enhance mechanical properties of the hybrid composites.

The PP/EVA/MMT nanocomposites were extensively investigated for the purposes of evaluating their mechanical properties, and it was predicted by different studies that the stiffness of the composites would increase [134]. The clay incorporation technique also had a substantial impact on the dynamic mechanical and rheological characteristics of PP-EVA/clay nanocomposites. These characteristics may be used in a variety of technical applications, such as the automotive sector, which often requires materials with high stiffness. The usage of these materials can also improve appearance, dimensional stability, and dimensional conformity [135].

Table 3 shows the Young's modulus, elongation at break and tensile strength of various polymeric blends and nanocomposites samples studied by Castro-Landinez et al. [136]. A $21 \%$ increase in stiffness was seen for blends with EVA28 while it was 15\% with EVA12 as compared with EVOH systems. On comparing EVOH44 and EVOH38 blends, an increment of $0.8 \%$ and $10.2 \%$ in stiffness was observed. This may be because of addition of a stiffer copolymer (EVOH) than EVA. The results demonstrated that the MMT showed better interactions with PP/EVA blends because they operate as a reinforcing agent than the effect on the PP/EVOH blends. Interestingly, with the introduction of clay into polymeric blends for both $\mathrm{PP} / \mathrm{EVA}$ and $\mathrm{PP} / \mathrm{EVOH}$, the elongation at break and the tensile strength showed no significant change [136]. 
Table 3. Mechanical properties (Young's modulus, elongation at break and tensile strength) of polymeric blends and nanocomposites samples.

\begin{tabular}{|c|c|c|c|c|}
\hline Type of Material & Matrix & $\begin{array}{l}\text { Young's Modulus } \\
\text { (GPa) }\end{array}$ & $\begin{array}{c}\text { Elongation at Break } \\
(\%)\end{array}$ & $\begin{array}{c}\text { Tensile Strength } \\
\text { (MPa) }\end{array}$ \\
\hline \multirow{5}{*}{ Neat Polymers } & PP & $0.96 \pm 0.04$ & $690 \pm 10$ & $22.30 \pm 4.00$ \\
\hline & EVA12 & $0.10 \pm 0.05$ & $825 \pm 60$ & $14.88 \pm 3.27$ \\
\hline & EVA28 & $0.09 \pm 0.04$ & $900 \pm 50$ & $16.24 \pm 4.21$ \\
\hline & EVOH38 & $2.32 \pm 0.21$ & $43 \pm 21$ & $57.41 \pm 3.12$ \\
\hline & EVOH44 & $1.83 \pm 0.23$ & $48 \pm 18$ & $45.05 \pm 7.34$ \\
\hline \multirow{4}{*}{ Polymeric blends } & & $0.65 \pm 0.04$ & $587 \pm 45$ & $17.62 \pm 0.64$ \\
\hline & PP/EVA12 PP/EVA28 & $0.60 \pm 0.01$ & $310 \pm 42$ & $16.85 \pm 0.63$ \\
\hline & PP/EVOH38 PP/EVOH44 & $1.16 \pm 0.05$ & $6 \pm 2$ & $20.28 \pm 2.51$ \\
\hline & & $1.13 \pm 0.04$ & $16 \pm 7$ & $19.01 \pm 1.89$ \\
\hline \multirow{4}{*}{$\begin{array}{l}\text { Nanocomposites } \\
\text { materials }\end{array}$} & $\mathrm{PP} / \mathrm{EVA12/MMT}$ & $0.76 \pm 0.02$ & $574 \pm 58$ & $17.89 \pm 0.61$ \\
\hline & PP/EVA28/MMT & $0.75 \pm 0.01$ & $353 \pm 55$ & $17.42 \pm 0.45$ \\
\hline & $\mathrm{PP} / \mathrm{EVOH} 38 / \mathrm{MMT}$ & $1.29 \pm 0.02$ & $13 \pm 8$ & $19.95 \pm 1.05$ \\
\hline & $\mathrm{PP} / \mathrm{EVOH} 44 / \mathrm{MMT}$ & $1.15 \pm 0.04$ & $19 \pm 10$ & $17.94 \pm 0.83$ \\
\hline
\end{tabular}

PP-polypropylene. EVA12-Ethylene vinyl acetate (Elvax660) with $12 \mathrm{wt} . \%$ of vinyl acetate monomer content. EVA28-EVA28, with $28 \mathrm{wt} . \%$ of vinyl acetate monomer content. EVOH38-Ethylene vinyl alcohol with $38 \mathrm{~mol} \%$ of ethylene monomer content. EVOH44- 44 mol.\% of ethylene monomer content.

Shikaleska et al. [137] reported that poly(ethylmethacrylate) (PEMA) and MMT clay particles have a considerable effect on the mechanical properties of poly(vinylchloride) (PVC)/PEMA 90/10 blend composite. A PVC/PEMA combination with a lower Young's modulus and higher tensile strength and elongation at break than clean PVC is observed. It is intended to achieve a better Young's modulus, less tensile strength and elongation at break by incorporating MMT clay particles into PVC/PEMA material. This indicated that the MMT clay addition had a greater effect on the tensile strength and elongation at break than on the elastic modulus. Sengwa et al. [138] revealed that the dispersion of MMT in poly(vinyl alcohol) (PVA), poly(vinyl pyrrolidone) (PVP), poly(ethylene oxide) (PEO), and poly(ethylene glycol) (PEG) matrices will improve the mechanical properties of the blended nanocomposites. These synthetic polymers, PVA, PVP, PEO, and PEG are hydrophilic in nature.

Recently, Ramesh et al. [139], worked on the combination of PLA-treated KF-MMT, proving that better properties were obtained in blend form than with the system alone. In order to obtain superior characteristics, it is therefore required to combine kenaf fiber (KF)—MMT and PLA. Currently, OMMT and MMT are of great importance. Both have potential tendency to improve the mechanical properties of any polymer [139]. In contrast to PLA/TKF biocomposites, the flexural, impact and tensile strengths were increased by $46.4 \%, 10.6 \%$ and $5.7 \%$, respectively, when $1 \mathrm{wt} . \%$ MMT was added to PLA/TKF/MMT hybrid biocomposites [139]. Adding MMT above $1 \mathrm{wt.} \%$, the above mechanical properties decreased. Ramesh et al. [34] indicated that tensile, flexural, and impact properties were increased by the addition of MMT clay with the treatment of $(6 \%) \mathrm{NaOH}$-treated kenaf fiber/aloe vera fiber/PLA. The mechanical properties were improved by hybridised $15 \mathrm{wt} . \%$ kenaf, $15 \mathrm{wt} . \%$ aloe vera fibers and $1 \mathrm{wt} . \%$ MMT clay-incorporation. For hybrid nanocomposite, the tensile strength, flexural strength, and impact strength were improved by $5.24 \%, 2.46 \%$, and $37.10 \%$ after adding $1 \mathrm{wt} . \%$ MMT clay compared to neat PLA, while the tensile and flexural modulus were increased by $24.61 \%$ and $108.09 \%$. The tensile strength was decreased by $14.05 \%$ after the addition of $3 \mathrm{wt} . \%$ MMT clay as compared with neat PLA. The tensile strength was reduced because of the formation of agglomerations by $3 \mathrm{wt} . \%$ MMT clay and micro-evasion. For the same reason, the impact strength also decreased by $14.88 \%$ [34]. 


\section{Thermal Properties of MMT/Natural Fiber Reinforced Polymer Nanocomposites 6.1. MMT-Reinforced Natural Fiber Polymer Nanocomposites}

The biodegradability of polymeric materials can be accelerated by novel strategies developed as a result of consumer pressure as well as environmental legislation. In this scenario, the production of natural fiber-reinforced biocomposites is a step toward minimizing the environmental footprint of non-biodegradable polymeric materials [140,141]. A number of studies that have been conducted on the biodegradation natural fiber reinforced polymeric materials biodegradation have yielded promising results $[142,143]$. The advantages of biocomposites emerge from the properties of natural fibers, e.g., low cost, light weight, sustainability, tolerable specific mechanical properties, and environmental compatibility. Nevertheless, the lack of interfacial adhesion, lower processing temperature, as well as high water absorption potential have made natural fiber reinforced composites less appealing. Moisture penetration may negatively impact the mechanical properties and promote fungus growth, which can aid in composites' degradation [144]. As a result, characterization of the morphological, moisture exposure, and other performance characteristics of natural fiber-reinforced composites is critical for assessing their effectiveness when considering natural fibers as a feasible reinforcement and validating the longevity of such products. Nanoclays are regarded as among the most essential particles for the reinforcement of polymeric matrices and for promoting new and improved properties, e.g., increased stiffness, toughness, flame resistance, as well as gas barrier activity [145-148]. MMT is the most promising nanoclay of them all. The clay structure is composed of the stacking of hundreds of sheets or platelets in the manner of book pages [145]. The addition of nanoclays to natural fiber reinforced plastic materials as load-bearing components is expected to compensate for the deficiencies in natural fiber reinforced composite materials.

Another important piece of information needed to determine the thermomechanical performance of the hybrid composites is obtained by determining the elastic character of the material at a higher frequency and under the influence of heat. Dynamic mechanical analysis (DMA) is the most common analysis done to evaluate the rheological properties of hybrid composites represented by storage modulus $\left(E^{\prime}\right)$, loss modulus $\left(E^{\prime \prime}\right)$ and tan $\delta$. The $E^{\prime}$ focuses on the elastic behaviour of the material subjected to a sinusoidal stress which provides information about properties including the stiffness, load-bearing capacity, cross-link density and interfacial strength of between fiber and matrix [149-151], whilst, the $\mathrm{E}^{\prime \prime}$ indicates a higher ability to dissipate energy. The $\mathrm{E}^{\prime \prime}$ also indicates better the damping properties to reduce damaging forces caused by mechanical energy. Meanwhile, $\tan \delta$ provides information regarding the damping parameter of the composite material. A high $\tan \delta$ value indicates a high non-elastic strain component, whilst its curve is attributed to the energy dissipation as heat during each deformation cycle [146].

A study conducted by Khaliq Majeed et al. [152] on the effect of maleic anhydridegrafted polyethylene (MaPE) compatibiliser on the thermal properties of rice husk (RH) and nanoclay-filled low-density polyethylene (LDPE) composite films demonstrated that adding RH and MMT nanofiller to the LDPE matrix increased the $\mathrm{T}_{\mathrm{m}}$ by $1{ }^{\circ} \mathrm{C}$. This could be because the dispersed nanoclay particles acted as a barrier to heat conduction to crystallites until the temperature rose to a point where the heat flow was sufficient to melt the crystallites. The addition of MaPE to RH and MMT-filled LDPE resulted in a clear shoulder near the main peak that became more noticeable with higher MaPE concentrations. No significant difference was observed in crystallization temperatures between both uncompatibilised and compatibilised composite films, indicating the absence of significant MMT nucleation activity in the LDPE-based system [152,153]. Seetharaman and co-workers [154] studied the influence of MMT nanoclay on jute fiber/unsaturated polyester nanocomposites in terms of dynamic mechanical analysis. The addition of nanoclay increased the $\mathrm{E}^{\prime}$, as a result of the imparting effect of filler reinforcements that are more rigid compared to the polymer matrix [155]. The temperature of the glass transition was increased from 109 to $115^{\circ} \mathrm{C}$, but this resulted in a decrease in the damping factor. This might be because uniform molecular motion requires a large amount of thermal energy 
and the nanocomposites' energy accumulation capacity that can be improved by adding more fiber. The drop of the $E^{\prime}$ close to the glass transition temperature $\left(T_{g}\right)$ was a result of the composite's softness. Incorporating nanoclay as the composites' filler improved the $E^{\prime}$ due to the nanoclay that functions as a stiffening agent, reducing the polymeric molecules' movement [156]. Besides, it was also observed that with a nanoclay content up to $5 \mathrm{wt} . \%$ in the polyester, along with $25 \mathrm{wt}$.\% jute fiber content, significantly increased the $\mathrm{E}^{\prime}$ more than with other MMT nanoclays. This finding resulted from cluster formation in the composite as the nanoclay content was increased. As a result, it developed heterogeneity and, as a consequence, a weak bond was formed between the matrix and the fiber. It was discovered that the $5 \mathrm{wt}$ \% nanoclay and $25 \mathrm{wt}$ \% jute content composites exhibited a lower $\tan \delta$ peak, which was attributed to the enhanced fiber/matrix adhesion, decreased molecular mobility, and improved load carrying capacity. These observations were obtained from the additions of jute fiber and nanoclay as primary and secondary reinforcement, respectively, producing a positive composite hybridization effect. This phenomenon led to more loads and energy being borne by the hybrid composite, which increased the composite material's performance. By incorporating nanoclay, energy was dissipated more efficiently at the interface, thereby increasing the material's stiffness and $T_{g}$ value [154].

In the work performed by Ramesh et al. [39], the preparation of PLA and PLA hybrid biocomposites was carried out using a twin-screw extruder, two-roll mills, and a compression molding method. 30\% treated aloe vera fiber and $0 \mathrm{wt} . \%, 1 \mathrm{wt} . \%, 2 \mathrm{wt} . \%$, and $3 \mathrm{wt} \%$ MMT nanoclay filler were used in the PLA-based biocomposites fabrication to study the effect of MMT clay on the thermal properties of the produced PLA and PLAhybrid biocomposites. The PLA-hybrid biocomposites' mechanical, thermal, and water resistance characteristics were enhanced with MMT clay addition. The findings of thermogravimetric analysis (TGA) analysis revealed improved decomposition temperature of the PLA-biocomposites with MMT clay inclusion. Adding 3 wt. \% MMT clay improved the decomposition temperature of PLA biocomposites from $295{ }^{\circ} \mathrm{C}$ to $299{ }^{\circ} \mathrm{C}$ in $\mathrm{T} 10 \%$, similarly, from $338{ }^{\circ} \mathrm{C}$ to $350{ }^{\circ} \mathrm{C}$ in $\mathrm{T} 75 \%$.

TGA was employed to study the thermal behaviour and stability of PLA and PLAhybrid biocomposites. The $10 \%$ and $75 \%$ weight loss temperatures [157] were set as the baselines for analyzing the thermal stability of both PLA and PLA-hybrid biocomposites. Improvements in the T10\% and T75\% of PLA-hybrid biocomposites were observed from $295^{\circ} \mathrm{C}$ to $299^{\circ} \mathrm{C}$ and $338^{\circ} \mathrm{C}$ to $350{ }^{\circ} \mathrm{C}$, respectively (Table 4). The thermal decomposition took place in three stages: (1) moisture evaporation at temperatures of up to $150{ }^{\circ} \mathrm{C},(2)$ lignin, cellulose, and hemicellulose degradations, and (3) depolymerization of PLA and MMT clay [158-163]. The thermal stability of neat PLA is reduced with natural fiber addition that could be generally be explained by the decrease in polymer thermal stability with natural fiber addition. For PLA (P) and PLA-hybrid biocomposites (A1-containing 1 wt.\% MMT, A2-containing 2 wt.\% MMT, and A3-containing 3 wt.\% MMT) 10\% mass losses were degraded at $295^{\circ} \mathrm{C}, 296^{\circ} \mathrm{C}, 299^{\circ} \mathrm{C}$, and $299{ }^{\circ} \mathrm{C}$, respectively. Approximately $75 \%$ of the biocomposites' weights were loss at $338^{\circ} \mathrm{C}, 342{ }^{\circ} \mathrm{C}, 344^{\circ} \mathrm{C}$, and $350{ }^{\circ} \mathrm{C}$, respectively. For $10 \%$ and $75 \%$ weight losses, the neat PLA degraded at $327^{\circ} \mathrm{C}$ and $358^{\circ} \mathrm{C}$, correspondingly. The PLA-hybrid biocomposites (A3) containing $3 \mathrm{wt} \%$ MMT exhibited the highest decomposition temperatures $\left(299{ }^{\circ} \mathrm{C}\right.$ in $10 \%$ and $350{ }^{\circ} \mathrm{C}$ in $\left.75 \%\right)$ than other biocomposites $(\mathrm{A}$, $\mathrm{A} 1$, and A2). These enhancements occurred due to the MMT clay that acted as a barrier, restricted chain mobility, and hindered the decomposition progress. A similar finding was found in a previous study, where hybridization resulted in enhanced thermal stability of the hybrid biocomposites [164]. 
Table 4. TGA analysis sample of MMT clay reinforced treated aloe vera fiber/PLA hybrid biocomposites.

\begin{tabular}{cccc}
\hline & & \multicolumn{2}{c}{ Weight Loss, Decomposition Temperature } \\
Sample & Denotation & $\mathbf{1 0 \%}$ & $\mathbf{7 5 \%}$ \\
\cline { 3 - 4 } & & 327 & 358 \\
PLA & $\mathrm{P}$ & 295 & 338 \\
PLA-30TAF & $\mathrm{A}$ & 296 & 342 \\
PLA-30TAF-1MMT & A1 & 299 & 344 \\
PLA-30TAF-2MMT & A2 & 299 & 350 \\
PLA-30TAF-3MMT & A3 & & \\
\hline
\end{tabular}

PLA $=$ polylactic acid, $\mathrm{TAF}=$ treated aloe vera fiber, $\mathrm{MMT}=$ montmorillonite.

Sajna et al. [165] successfully prepared green nanocomposites of poly(lactic acid) (PLA)/banana fiber/MMT nanoclay using melt-blending followed by injection molding techniques. Untreated and chemically modified banana fibers as well as organically modified MMT nanoclay with methyltallow bis(2-hydroxyethyl) ammonium (Cloisite 30B) were added as reinforcement into the PLA matrix. Numerous chemical modifications were performed on the banana fibers, including mercerization, silane, sodium lauryl sulphate and permanganate treatments, and a combination of mercerization and silane treatments. To study the effects of banana fiber chemical modification and nanoclay incorporation, the bionanocomposites and biocomposites were characterized via dynamic mechanical analysis (DMA), differential scanning calorimetry (DSC), TGA, and heat deflection temperature (HDT) studies. DMA results showed that the bionanocomposites' $\mathrm{E}^{\prime}$ increased with respect to the neat PLA biocomposites. In general, higher dissipation energy is exhibited by composites having poor interfacial bonding, thus, demonstrating a high damping peak magnitude than composites possessing better matrix-filler interfacial bonding that bears higher stress transfer and less dissipation energy [166]. The damping peak of the PLA/SiB/C30B bionanocomposites showed decreasing $\tan \delta$ compared to neat PLA, PLA/UTB, and PLA/SiB biocomposites that was probably due to the excellent filler-matrix interfacial bonding [165]. The DSC findings demonstrated insignificant changes in glass transition temperature. However, both silane-treated fiber and C30B nanoclay additions improved the PLA crystallites nucleation and raised the melting temperatures. There is a relationship between the degree of crystallinity of semicrystalline polymer PLA and its mechanical properties as well as thermal degradation temperature [167]. A sample with a low crystallinity degree degraded rapidly and possessed a lower strength [168]. TGA and derivative thermogravimetry (DTG) analyses concluded that the fillers addition increased the initial and maximum degradation temperatures of biocomposites and bionanocomposites. Banana fiber and C30B both played a significant role in preventing gas release during the thermal degradation process, which resulted in a delay in weight loss [169].

Kumar and Singh [170] prepared hybrid composite materials by incorporating MMT modified with dimethyl dehydrogenated tallow quaternary ammonium cation (Cloisite), layered silicates, and microcrystalline cellulose (MCC) into the thermoplastic polymer. Three types of composites were prepared using an ethylene-propylene (EP) copolymer as the thermoplastic polymer matrix and a maleated EP (MEP) copolymer as the compatibiliser: (i) cellulose melt mixing with thermoplastics [I], (ii) clay melt mixing with thermoplastics [II], and (iii) cellulose melt mixing with thermoplastic clay nanocomposites [III] (Table 5). Characterisation of the composites was conducted via DSC and TGA. The marginal increase in melting point of composites containing clay (TC05-TC15) might be ascribed to the heat deflection behaviour of layered silicates and the constraint of thermal motion of macromolecular chains within the silicate layers [171,172]. According to Tyan et al. [173], thermal expansion in nanocomposites was also reduced during melting because macromolecular chains sandwiched between silicate layers and oriented in a plane (platelet) direction tended to relax in the opposite direction of their original orientation. It might be due to silicate layers that are significantly more rigid than polymer molecules and do not deform, making it difficult for polymer molecules to relax. 
Transitions beyond the matrix melting point in ternary composites can be described by the presumption that the layered silicates and rising cellulose fiber concentration increased phase separation and appeared to accelerate heterogeneous nucleation to crystallize at higher temperatures via their role as nucleation centers [174]. Table 6 presents the maximum decomposition of (host) matrix $\mathrm{T}_{\mathrm{d}}\left({ }^{\circ} \mathrm{C}\right)$ for all samples. $\mathrm{T}_{\mathrm{d}}$ was found to be approximately $5{ }^{\circ} \mathrm{C}$ higher in cellulose composites (CC05) and nanocomposites NC05 than in the neat polymer matrix. A similar effect was observed with the ternary composite (TC05), with an increase of approximately $13{ }^{\circ} \mathrm{C}$ as compared to the polymer matrix. The rise in $\mathrm{T}_{\mathrm{d}}$ for composites containing clay was well explained by some authors who showed that the degraded products diffusion could be limited/slowed down in between the silicate layers $[175,176]$. The effect of silicate layers on the thermal mobility of molecules is dependent on the orientation of the polymer molecules, rigidity, and stability of the silicate layers. The increment in decomposition temperature, on the other hand, might be insignificant in terms of thermal stability improvement for natural fiber reinforced composites.

Table 5. Composition of composites prepared ${ }^{\mathrm{a}}$.

\begin{tabular}{|c|c|c|c|c|c|}
\hline Sample No. & $\begin{array}{c}\text { Neat EP Copolymer } \\
(w t . \%)\end{array}$ & $\begin{array}{c}\text { Maleated EP } \\
\text { Copolymer (wt.\%) }\end{array}$ & Cellulose (wt.\%) & $\begin{array}{c}\text { Cloisite }^{\circledR} 20 \mathrm{~A} \\
\text { (wt.\%) }\end{array}$ & Code \\
\hline 1 & 100 & - & - & - & Neat EP \\
\hline 2 & - & 100 & - & - & MEP \\
\hline 3 & 57 & 38 & 5 & - & $\mathrm{CC} 05$ \\
\hline 4 & 54 & 36 & 10 & - & CC10 \\
\hline 5 & 51 & 34 & 15 & - & CC15 \\
\hline 6 & 57 & 38 & - & 5 & NC05 \\
\hline 7 & 54 & 36 & 5 & 5 & TC05 \\
\hline 8 & 51 & 34 & 10 & 5 & TC10 \\
\hline 9 & 48 & 32 & 15 & 5 & TC15 \\
\hline
\end{tabular}

a Neat EP/MEP ratio is 60/40. Ethylene-propylene (EP); Maleated ethylene-propylene (MEP); CC = cellulose composite; TC = ternary composite; $\mathrm{NC}=$ nanocomposites (i.e., without cellulose).

Table 6. Melting and decomposition temperatures.

\begin{tabular}{ccc}
\hline Samples & $\mathbf{T}_{\mathbf{m}}\left({ }^{\circ} \mathbf{C}\right)$ & $\mathbf{T}_{\mathbf{d}}\left({ }^{\circ} \mathbf{C}\right) \mathbf{E P}$ \\
\hline Neat EP & 165.8 & 453.3 \\
MEP & 166.5 & 443.2 \\
CC05 & 166.7 & 458.1 \\
CC10 & 168.2 & 461.1 \\
CC15 & 168.7 & 463.1 \\
NC05 & 165.7 & 458.9 \\
TC05 & 167.6 & 466.4 \\
TC10 & 169.3 & 483.3 \\
TC15 & 170.0 & 482.1 \\
\hline
\end{tabular}

Ethylene-propylene (EP); Maleated ethylene-propylene (MEP); CC = cellulose composite; TC = ternary composite; $\mathrm{NC}=$ nanocomposites (i.e., without cellulose).

\subsection{MMT-Reinforced Hybrid Natural Fiber Polymer Nanocomposite}

Compression molding was used to develop hybrid fiber reinforced polymer composites from kenaf, and aloe vera fibers, PLA, and MMT clay (Table 7). The fiber and MMT clay hybridization effects on their water absorption, mechanical, biodegradability, and thermal properties were investigated [34]. To enhance the bonding and compatibility of kenaf and aloe vera fibers with the PLA matrix, they were treated with a $6 \%$ sodium hydroxide solution. The results revealed that the addition of MMT clay improved the thermal properties of the biocomposites. Adding $3 \mathrm{wt}$ \% MMT clay to the biocomposite increased 
its decomposition temperature from 280 to $307^{\circ} \mathrm{C}$ at $\mathrm{T}_{10}$ and $337^{\circ} \mathrm{C}$ to $361{ }^{\circ} \mathrm{C}$ at $\mathrm{T}_{75}$. SEM analysis revealed that MMT clay significantly enhanced the compatibility and bonding of fibers and PLA. The MMT clay at $3 \mathrm{wt} . \%$ is evenly distributed throughout the PLA matrix and the TEM result indicated that as the MMT content increased up to $6 \mathrm{wt}$.\%, the quality of the MMT dispersion declined due to higher number of agglomerations. The key objective of the research was to study the effects of fiber hybridization and MMT clay content on the thermal characteristics and internal bonding behaviour of PLA/TKF/TAF/MMT hybrid bionanocomposite that was crucial to synchronizing the properties.

Table 7. TGA Characterisation of $\mathrm{P}, \mathrm{S}, \mathrm{A}, \mathrm{H}, \mathrm{H} 1$, and $\mathrm{H} 3$ composites.

\begin{tabular}{cccc}
\hline Code & Sample & Weight Loss, Decomposition Temperature $\left({ }^{\circ} \mathbf{C}\right)$ \\
$\mathbf{1 0}(\mathbf{\%})$ & $\mathbf{7 5}(\mathbf{\%})$ \\
\hline $\mathrm{P}$ & Polylactic acid (PLA) & 327 & 358 \\
$\mathrm{~S}$ & Polylactic acid/treated kenaf fiber (PLA/TKF) & 280 & 337 \\
$\mathrm{~A}$ & Polylactic acid/treated aloe vera fiber PLA/TAF & 295 & 338 \\
$\mathrm{H}$ & Polylactic acid/ treated kenaf fiber/treated aloe vera & 291 & 343 \\
$\mathrm{H} 1$ & fiber (PLA/TKF/TAF) & 301 & 346 \\
$\mathrm{H} 3$ & Polylactic acid/treated kenaf fiber/treated aloe vera & 307 \\
\end{tabular}

From the findings, hybridization improved the biocomposites' thermal stability, as evidenced by the corresponding TGA curves. The temperature deviations of $10 \%$ and $75 \%$ weight losses from the baselines, $\mathrm{T}_{10}$ and $\mathrm{T}_{75}$, respectively, were the indicators used for assessing the manufactured biocomposites' thermal stability that was adapted on a previous work [157]. Improvements in the $\mathrm{T}_{10}$ and $\mathrm{T}_{75}$ of PLA/TKF biocomposite from $280{ }^{\circ} \mathrm{C}$ to $291{ }^{\circ} \mathrm{C}$ and $337^{\circ} \mathrm{C}$ to $343^{\circ} \mathrm{C}$ after hybridization, respectively, were observed. The TAF's high thermal stability was found to balance the TKF's poor thermal stability. The thermal decomposition took place in three stages: (1) moisture evaporation at temperatures up to $150{ }^{\circ} \mathrm{C}$, (2) lignin, cellulose, and hemicelluloses degradation, and (3) PLA depolymerization. Typically, the polymer's thermal stability declines with natural fiber addition [177-179]. A similar phenomenon was observed with TAF and TKF additions to the neat PLA. However, adding MMT clay resulted in a thermal stability improvement. The 3 wt. \% MMT clay reinforced PLA/TKF/TAF composite showed better thermal stability than other bionanocomposites with $280{ }^{\circ} \mathrm{C}$ to $307^{\circ} \mathrm{C}$ at $\mathrm{T} 10$ and $337{ }^{\circ} \mathrm{C}$ to $361^{\circ} \mathrm{C}$ at T75 improvements than the neat PLA that degraded at $327^{\circ} \mathrm{C}$ and $358{ }^{\circ} \mathrm{C}$, respectively. Similarly, the $3 \mathrm{wt}$ \% MMT clay reinforced PLA/TKF/TAF hybrid bionanocomposite was higher than neat PLA in terms of thermal stability, with an improvement of from $358{ }^{\circ} \mathrm{C}$ to $361^{\circ} \mathrm{C}$ at T75. This finding was due to MMT clay that functioned as a barrier, constrained chain mobility, and hindered the degradation process. This was aligned with previous studies $[39,146,171]$. It was concluded that the MMT clay incorporation improved the PLA-based biocomposites' thermal stability.

A thermal properties investigation of MMT-incorporated polypropylene (PP)/RH hybrid nanocomposites was performed by Majeed et al. [32]. TGA was employed to study the thermal behaviour of neat PP composites, and PP nanocomposites with and without the presence of compatibiliser. The temperatures of thermal degradation at $10 \%$ and 50\% weight losses (T10 and T50) attained from the thermogravimetry (TG) and DTG curves (Figure 5) are presented in Table 8. A one-step degradation process was exhibited by the PP, from $425{ }^{\circ} \mathrm{C}$ to $550{ }^{\circ} \mathrm{C}$. On the other hand, $\mathrm{RH}$ followed a three-step thermal decomposition (water evaporation, cellulosic substances degradation, and noncellulosic materials degradation), as presented in TGA/DTG curves. From the observation, RH demonstrated similar thermal behaviour with other lignocellulosic fibers [180-182]. PP degradation was initiated at $299{ }^{\circ} \mathrm{C}$ and was increased with $\mathrm{RH}$ incorporation into the 
matrix that could be ascribed with the lower RH thermal degradation than PP. $10 \%$ and 50\% weight losses of RH-reinforced PP (PR) occurred at $311^{\circ} \mathrm{C}$ and $437^{\circ} \mathrm{C}$, correspondingly, and adding more PP-g-MAH into the PP/RH (PRC) composites slightly altered the PP/RH decomposition temperature. This observation might be due to the improved interaction between RH fibers and the PP bridged by PP-g-MAH. Nevertheless, the MMT/PP-g$\mathrm{MAH}$ addition resulted in a more significant thermal stability improvement in the $\mathrm{PP} / \mathrm{RH}$ system owing to the existence of the uniformly dispersed delaminated MMT platelets. Namely, thermal degradation improvement is highly influenced by MMT delamination and exfoliation in nanocomposites [183], as reported in [184]. MMT addition also limits the polymer chains movement owing to the presence of dispersed MMT platelets that are rigid and impermeable and assumed to decrease heat conduction [185].

Table 8 presents the peaks of melting and crystallization for neat PP observed at approximately $163^{\circ} \mathrm{C}$ and $117^{\circ} \mathrm{C}$, respectively. The melting temperature, $\mathrm{T}_{\mathrm{m}}$, remained unchanged with further PP-g-MAH and/or MMT incorporations. In contrast, a slight decrement in the crystallization peak, $\mathrm{T}_{\mathrm{c}}$ was observed with MMT and/or PP-g-MAH incorporations. The MMT addition to the PP/RH composite system yielded partial increment that later became more significant with compatibiliser addition, similar to the PRMC nanocomposites. Changes were found in the characteristics and the nucleation effect that might be associated with the incorporations of MMT and PP-g-MAH into PP. These findings, however, were inconsistent with the other studies [186]. The crystallinity increase from MMT/PP-g-MAH incorporation could be caused by the higher crystallinity of PP-g-MAH and/or the improved interfacial adhesion between MMT and PP [152,187]. Therefore, the increased crystallinity can be ascribed to the intercalation of PP chains between MMT platelets and their possible interaction, with MMT platelets acting as nucleation sites. Impermeable crystalline regions were thought to enhance stress transfer, which affected the overall mechanical properties of the composite. Consequently, the increase in crystallinity enhanced the composite system's mechanical properties in both dry and wet conditions.

Table 8. Thermal properties of neat PP and its composites.

\begin{tabular}{cccccc}
\hline Sample Designation & $\boldsymbol{T}_{\mathbf{m}}\left({ }^{\circ} \mathbf{C}\right)$ & $\boldsymbol{T}_{\mathbf{c}}\left({ }^{\circ} \mathbf{C}\right)$ & $\boldsymbol{X}_{\mathbf{c}}(\%)$ & $\boldsymbol{T}_{\mathbf{1 0}}\left({ }^{\circ} \mathbf{C}\right)$ & $\boldsymbol{T}_{\mathbf{5 0}}\left({ }^{\circ} \mathbf{C}\right)$ \\
\hline PP & 163.2 & 117.3 & 27.7 & 474 & 510 \\
PR & 162.9 & 120.1 & 29.6 & 311 & 437 \\
PRC & 163.1 & 119.2 & 30.1 & 318 & 441 \\
PRM & 163.0 & 116.1 & 29.9 & 315 & 440 \\
PRMC & 162.8 & 116.5 & 31.5 & 327 & 451 \\
\hline
\end{tabular}
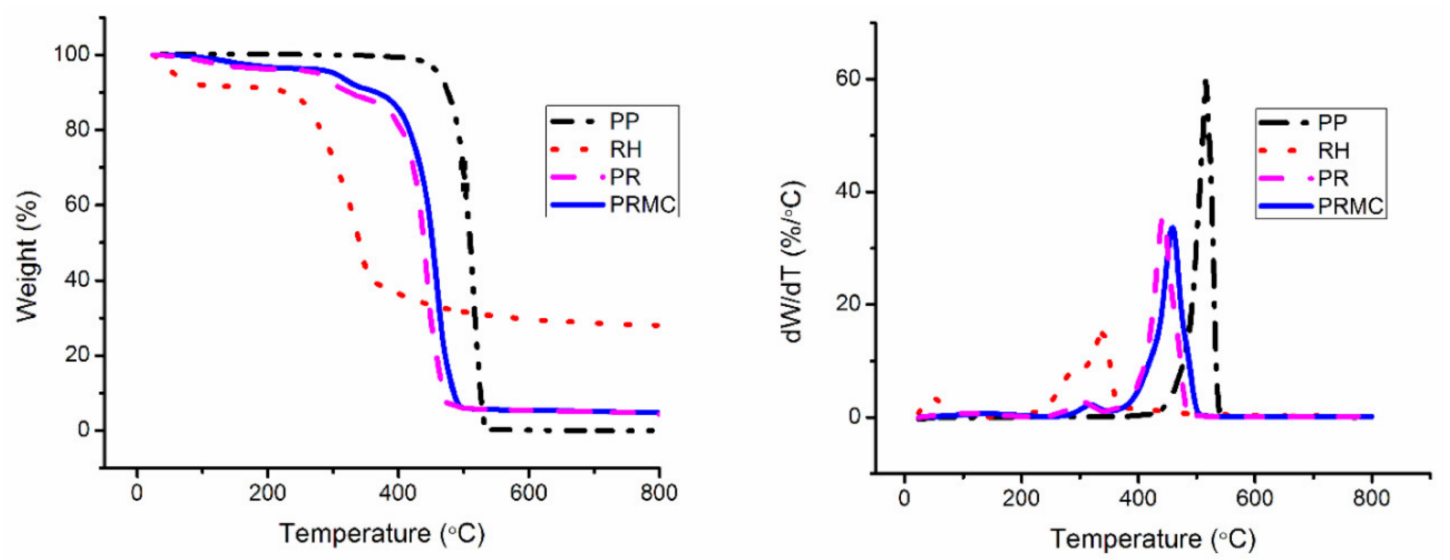

Figure 5. TG/DTG curves for neat PP, RH, and the representative composites. Reproduced from [32]. 
The study on the dynamic mechanical properties of the hybrid composites was done by Rajini et al. [188] by utilizing the coconut sheath/polyester (CS/PS) composites with different additions of MMT ( 0 to $5 \mathrm{wt} . \%$ ) to analyze their rheological properties. The authors discussed the effect of nanoclay dispersion on the composite system in the exfoliated and intercalated states, which contribute to the efficient stress transition resulting in secondary reinforcement in CS/PS composites. The authors also found improvement in the modulus of the composites, indicating the effect of the high surface-to-contact ratio of nanoclay on the polymer matrix. The strengthening effect of the nanoscale second phase also led to an improvement in the thermal stability of the composites. At $100{ }^{\circ} \mathrm{C}$, the $\mathrm{E}^{\prime}$ of $\mathrm{CS} / \mathrm{PS}$ composites was found to be $812 \mathrm{MPa}$ and increased to $1580 \mathrm{MPa}$ after the addition of $2 \%$ and $3 \%$ of MMT. However, the value of $E^{\prime}$ decreases after the addition of $5 \%$ of MMT due to the agglomeration of the MMT filler.

Another thorough study on the dynamic mechanical properties of hybrid natural composites with nanoclay addition was done by Chee et al. [146] with the combination of non-woven bamboo and woven kenaf reinforcement in epoxy composites. The dynamic mechanical properties of these hybrid composites were analyzed based on different types of nanoclays addition viz. organically modified OMMT, MMT and halloysite nanotube (HNT). The $\mathrm{E}^{\prime}$ of the composites in the glassy region were found to increase by $98.4 \%, 41.5 \%$ and $21.7 \%$ with the addition of OMMT, MMT and HNT, respectively. This improvement can be attributed to the toughening effect by the nanoclay, which limits the movement of the polymer chain. A similar trend was also observed for $\mathrm{E}^{\prime \prime}$ value. The $\mathrm{E}^{\prime \prime}$ value increase by $159 \%, 65.2 \%$ and $53.6 \%$ for OMMT, MMT and HNT, respectively, which indicates higher internal friction has been induced by the addition of nanoclay that leads to higher energy dissipation. Meanwhile, the tan $\delta$ peak was found to decrease after the addition of nanoclay, which was attributed to the higher damping properties of non-elastic deformation. The reduction in the magnitude of the peak can also be referred to as the interlocking mechanism between nanoclay, fibers and epoxy polymer which restricts the polymer chain movement. Among all samples, the BK/E-OMMT composite represents the lowest tan $\delta$ peak, indicating strong interfacial adhesion interaction that reduces energy dissipation at the interface.

\section{Flame Retardancy Properties of MMT/Natural Fiber Reinforced Polymer Nanocomposites}

Flame retardancy of composites is another important characteristic that can determine their applicability. This information can be obtained by several characterization methods such as by using vertical burning tester, horizontal burning tester, oxygen index detector, cone calorimeter, etc. From vertical burning, the burning rating of composites can be determined based on burning time, afterglow time and dripping behaviors and reported as V-0, V-1, and V-2. Meanwhile, burning rate can be obtained from horizontal burning. Additionally, an oxygen index detector can be used to check the limiting oxygen index (LOI) of the composites. Some combustion properties like time to ignition (TTI), heat release rate (HRR), peak of release heat (PHR), average heat release rate (HRR), total heat release (THR), mass loss rate (MLR) and char yield can be acquired by using cone calorimeter tests. In general, the flammability of the composites is determined by several factors including chemical, physical, microscopic, and phase structure. There are various ways that can be used to reduce the flammability of composites. One of the most popular techniques is to introduce flame retardant materials. Another way is to use a non-flammable filler that will reduce combustible materials in the systems [189].

Suwanniroj and Suppakarn conducted a study on flame retardancy enhancement of polybutylene succinate (PBS) by addition of hybrid filler. In this study water hyacinth fiber (WHF) and MMT was used as the fillers and ammonium polyphosphate (APP) was added as the flame retardant. APP is a phosphorus-nitrogen containing flame retardant and was chosen due to its low toxicity, high efficiency and effective in reducing smoke. Phosphoric acid, water, and ammonia gas are formed as APP decomposes. Ammonia gas dilutes the concentration of oxygen gas in the gas phase, whereas phosphoric acid reacts 
with the carbonaceous component to create carbon char on the composites surface. This char functions as a protective layer, preventing heat and mass transfer between the gas and condensed phases. PBS and four other compositions of composites were prepared and their flame retardancy properties were characterized by vertical and horizontal burning test and the details were presented in Table 9. The results show that the neat PBS is a flammable material. PBS has $16.39 \mathrm{~mm} / \mathrm{min}$ horizontal burning rate and unclassified (NC) rating for vertical burning test with severe melt-dripping and flaming material. The dripping material led to the ignition of cotton placed below the sample. Upon the addition of fillers, the horizontal fire-spread rate of the composites improved significantly. The $\mathrm{APP} / \mathrm{WHF} / \mathrm{PBS}$ and MMT/APP/WHF/PBS did not give horizontal burning rate as the composites extinguished themselves on removal from the ignition source. In addition, they obtained V-2 rating for vertical burning test with self-extinguish was less than 30 s. Moreover, melt dripping and ignition of absorbent cotton was still observed for these composites despite the addition of APP and MMT [190].

Table 9. Flammability properties of PBS and PBS composites.

\begin{tabular}{|c|c|c|c|c|c|}
\hline \multirow{2}{*}{ Sample } & \multicolumn{4}{|c|}{ Vertical Burning Test } & \multirow{2}{*}{$\begin{array}{l}\text { Horizontal Burning } \\
\text { Rate (mm/min) }\end{array}$} \\
\hline & $t_{1}(s)$ & Dripping & Cotton Ignition & Rating & \\
\hline PBS & $>30$ & Yes & Yes & $\mathrm{NC}$ & $16.39 \pm 0.34$ \\
\hline APP/WHF/PBS & $<15$ & Yes & Yes & $\mathrm{V}-2$ & No burning \\
\hline 1MMT/APP/WHF/PBS & $<30$ & Yes & Yes & $\mathrm{V}-2$ & No burning \\
\hline 3MMT/APP/WHF/PBS & $<30$ & Yes & Yes & $\mathrm{V}-2$ & No burning \\
\hline 5MMT/APP/WHF/PBS & $<30$ & Yes & Yes & $\mathrm{V}-2$ & No burning \\
\hline
\end{tabular}

Subasinghe et al., prepared PP/kenaf composites reinforced with an intumescent flame retardant (IFR), and two different types of nanofillers which were HNT and MMT to investigate their flammability properties. The neat PP, PP/kenaf composites $(\mathrm{KeC}), \mathrm{PP} / \mathrm{Kenaf} / \mathrm{IFR}$ (KeC-IFR), PP/Kenaf/IFR/HNT (KeC-IFR-HNT) and PP/Kenaf/IFR/MMT (KeC-IFR-MMT) was studied using a vertical burning tester. From the analysis, they found out that the neat PP showed an intense dripping starting within $15 \mathrm{~s}$ of first flame application and the time substantially increase with the addition of kenaf (52 s) and IFR (85 s). However, addition of $3 \% \mathrm{HNT}$ reduced the dripping time to $82 \mathrm{~s}$ and lowered the flammability performance. On the other hand, addition of $3 \%$ MMT had increased the flame retardancy properties at which the flame extinguished during the first $3 \mathrm{~s}$ of the first flame and the dripping delayed until 65 $\mathrm{s}$ of the second flame application. They deduced that in the presence of MMT, the sample's sustained combustion improved significantly. Further, the composites were analyzed by cone calorimeter and the details are presented in Figure 6. Based on the HRR data on Figure 6a, it can be seen that neat PP completely burned within $4 \mathrm{~min}$ with a value of $1145 \mathrm{~kW} / \mathrm{m}^{2}$. Upon the addition of kenaf fiber ( $30 \mathrm{wt} . \%$ ) the HRR value reduced by $36 \%$. Further reduction up to $67 \%$ was observed after the incorporation of IFR. This is due to the presence of a more stable intumescent char stabilized the unstable lignocellulose ash layer, which is form during combustion of kenaf. The presence of HNT and MMT nanoparticles enhanced the HRR value due to the formation of phosphocarbonaceous compound-containing aluminosilicate structures. As a comparison, KeC-IFR-MMT shows better performance with lower HRR value compare to the system with HNT. This can be linked to the viscosity and effective particle dispersion of the nanoparticles. From Figure $6 b$, the THR value is decreased after the addition of kenaf, IFR, HNT and MMT. Other important factors in the fire atmosphere for the composites are the amount of smoke release (SPR) and carbon monoxide production (COP) during combustion process. Figure $6 c$ shows KeC-IFR-MMT produce the least amount of smoke compare to other system. Meanwhile, the $\mathrm{KeC}$ system produced the least $\mathrm{CO}$ during combustion and the addition of IFR significantly increases CO production as depicted in Figure 6d [191]. 

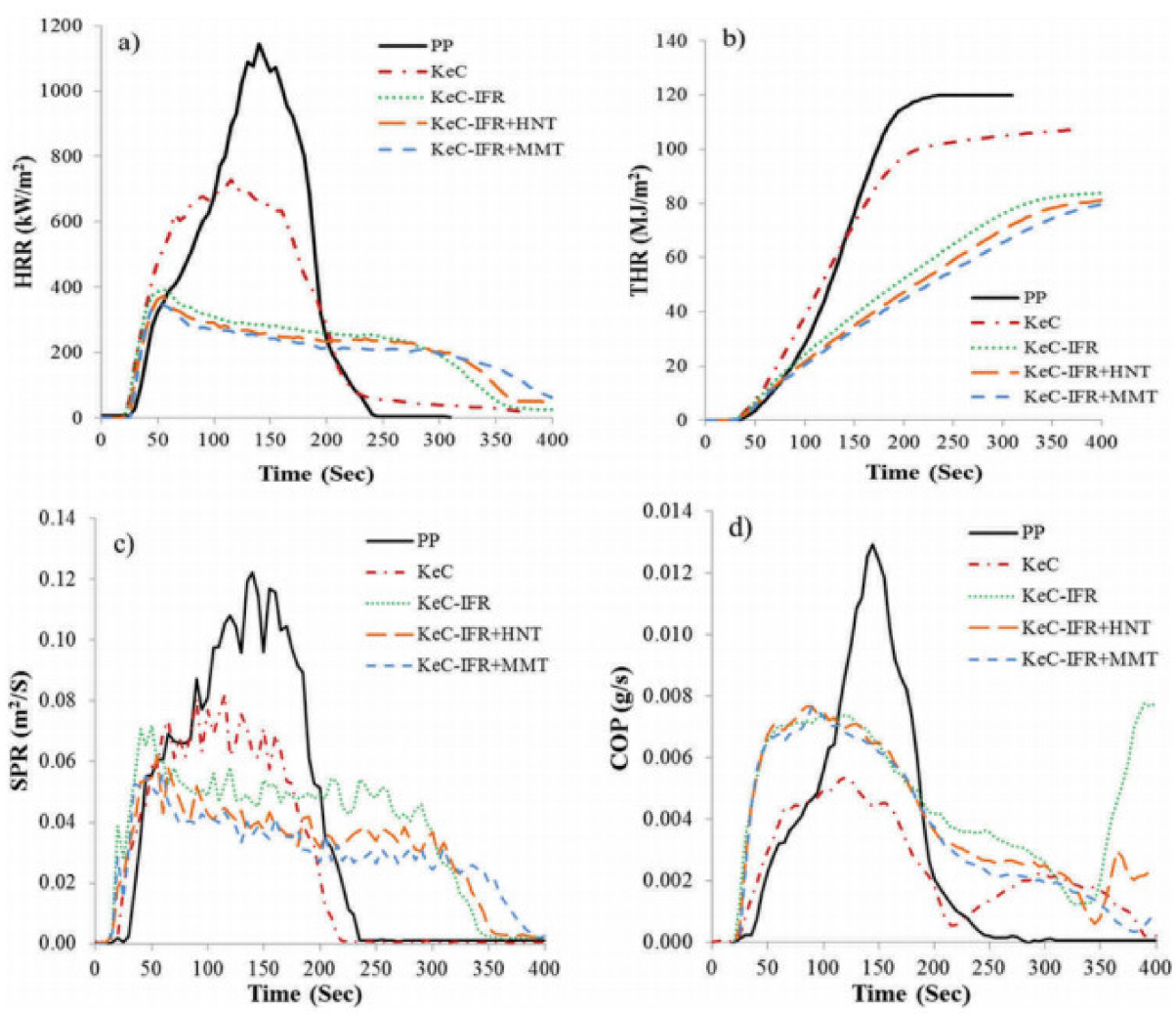

Figure 6. Flammability analysis by cone calorimeter: (a) HRR, (b) THR, (c) SPR, and (d) (COP). Reproduced from [191].

A study on the thermo-oxidative stability and flammability properties of bamboo/kenaf/nanoclay/epoxy hybrid nanocomposites was performed by Chee et al. Four systems were prepared in this study with three types of nanoclay which are HNT, MMT and organically modified MMT (OMMT). The ratio of bamboo (B) to kenaf (K) was fixed at 50:50 and the amount of nanoclay added is $1 \mathrm{wt} . \%$. Initially, the epoxy/nanoclay was mixed by in situ polymerization method. Then, the fiber reinforced epoxy/nanoclay was obtained through a hand lay-up technique. The samples were denoted as B/K/HNT, B/K/MMT and B/K/OMMT. The control sample (B/K/epoxy) was prepared omitting the nanoclay. The first analysis for flame retardancy was conducted by using horizontal burning test. All samples did not extinguish and were able to pass first and second gauge length. There was also no flame dripping observed for all samples. They suggest that the mat-form reinforcing fibers provide better structural integrity to the composites. Besides, addition of nanoclay delays the flame spread. The flammability rating for all samples were $\mathrm{HB} 40$ indicates that their burning rate is less than $40 \mathrm{~mm} / \mathrm{min}$ and they follow the sequence of $\mathrm{B} / \mathrm{K} /$ epoxy $>\mathrm{B} / \mathrm{K} / \mathrm{HNT}>\mathrm{B} / \mathrm{K} / \mathrm{MMT}>$ $\mathrm{B} / \mathrm{K} / \mathrm{OMMT}$. The flame delay was caused by the formation of a protective carbonaceous layer. This layer acts as a heat and flame insulator that limits the outgoing volatile gases and oxygen diffusion into the material. The B/K/OMMT composites shows better performance because of the presence of organic modifier enhances the catalytic effect during charring process; thereby produced a denser and more cohesive char. The second characterization was conducted to study the LOI of the nanocomposites. LOI can be defined as the lowest oxygen concentration needed to support flaming combustion of a material. From this analysis the $\mathrm{B} / \mathrm{K} / \mathrm{epoxy}$, $\mathrm{B} / \mathrm{K} / \mathrm{HNT}, \mathrm{B} / \mathrm{K} / \mathrm{MMT}$ and B/K/OMMT recorded LOI value of $19.8 \%, 22.9 \%, 22.9 \%$ and $27.7 \%$, respectively. The $\mathrm{B} / \mathrm{K} /$ epoxy is classified as combustible material as its LOI value is less than air oxygen content $(21 \%)$ whereas all the nanoclay hybrid composites are self-extinguished as they have LOI value greater than $21 \%$. This proves that addition of HNT and MMT nanoclays improve the flame retardant properties of the composites. This study found out that the LOI value increase with their ability to yield char. Higher amount of char will reduce the emission of flammable volatile and thus the oxygen level required to maintain flaming combustion will 
increase [192]. In addition, from the SEM analysis, the presence of filler, agglomerates and large tactoid particles on the surfaces of MMT/epoxy and HNT/epoxy nanocomposites fractioned items can be observed, while OMMT/epoxy nanocomposites showed more uniform dispersion.

Dutta and Maji prepared composites from PVC with microcrystalline cellulose (MCC) from RH and MMT by melt blending process at different MCC and MMT loadings. From the study, the LOI values for PVC/MCC and PVC/MMT are $44.4 \%$ and $46.7 \%$, respectively. Interestingly, hybrid PVC/MCC/MMT has a higher LOI value (50.0\%) compared to the individual systems. This is due to the formation of carbonaceous-silicate charred layer on the surface of the composites during combustion that retarded the heat transfer and thus delayed the decomposition rate. They suggested that the lower LOI value for single systems could be attributed to the agglomeration and poor dispersion of the components in the composites [193].

Composites from PLA/recycled bamboo chopstick fiber with multifunctional additive systems were produced by Wang and Shih. In this study, MMT was added as nanofiller, while APP and expandable graphene (EG) was used as flame retardants. Prior to mixing, the chopstick fiber (CF) underwent an alkaline treatment and then was chopped to obtain an average length of 2-4 mm. Both CF and MMT were treated with a silane coupling agent to obtain modified fibers and MMT (MCF and MOMMT). The composites were prepared by varying the amounts of APP and EG. The flammability characteristics were analyzed by a vertical burner tester. Details of the analysis are presented in Table 10. Based on the result, PLA can be classified as a flammable material with no rating in the UL94 standard. Similar pattern was found for the PLA containing $13 \mathrm{phr}$ of EG and $4 \mathrm{phr}$ of APP. A similar composition added with MCF and MOMMT produced a composite that passed the vertical burning test V-1 rating. Though dripping still occurred, the sample did not ignite the cotton. This proved that the addition of MCF and MOMMT enhanced the flammability of the composites. By modifying the amount EG and APP component, both PLA/23EG-4APP/MCF/MOMMT and PLA/13EG-8APP/MCF/MOMMT passed the V-0 rating, no dripping occurred and the cotton did not ignite.

Table 10. Flame retardance properties of PLA and PLA composites.

\begin{tabular}{|c|c|c|c|}
\hline Sample & Ignite the Cotton & Dripping & UL-94 Rating \\
\hline Polylactic acid (PLA) & Yes & Yes & NR \\
\hline $\begin{array}{l}\text { PLA + } 13 \text { phr expandable graphite }+4 \text { phr } \\
\text { ammonium polyphosphate (PLA/13EG-4APP) }\end{array}$ & Yes & Yes & NR \\
\hline $\begin{array}{l}\text { PLA }+13 \text { phr expandable graphite }+4 \text { phr } \\
\text { ammonium polyphosphate }+ \text { modified chopstick } \\
\text { fiber + modified montmorillonite } \\
\text { (PLA/13EG-4APP/MCF/MOMMT) }\end{array}$ & No & Yes & $\mathrm{V}-1$ \\
\hline $\begin{array}{l}\text { PLA }+23 \text { phr expandable graphite }+4 \text { phr } \\
\text { ammonium polyphosphate }+ \text { modified chopstick } \\
\text { fiber + modified montmorillonite } \\
\text { (PLA/23EG-4APP/MCF/MOMMT) }\end{array}$ & No & No & $\mathrm{V}-0$ \\
\hline $\begin{array}{l}\text { PLA }+13 \text { phr expandable graphite }+8 \text { phr } \\
\text { ammonium polyphosphate + modified chopstick } \\
\text { fiber + modified montmorillonite } \\
\text { (PLA/13EG-8APP/MCF/MOMMT) }\end{array}$ & No & No & $\mathrm{V}-0$ \\
\hline
\end{tabular}

Further, photographic images of the composites after combustion process are shown in Figure 7. It is evident from the image, that the PLA had severe dripping problems. Char residues formation can be observed for the composites, especially for the PLA/23EG$4 \mathrm{APP} / \mathrm{MCF} / \mathrm{MOMMT}$. They deduced that the addition of EG promoted the char yield in the presence of APP. During burning, EG was the first to degrade and expanded into a worm-like and loose porous char. This will inhibit oxygen and heat from permeating the substrate materials. After that, APP decomposed and produced polyphosphoric and ultraphosphoric acids, which catalyzed PLA to form a dense, continuous, and sealed 
char layer. This char layer protected the inner materials and limited the degradation of PLA [194].

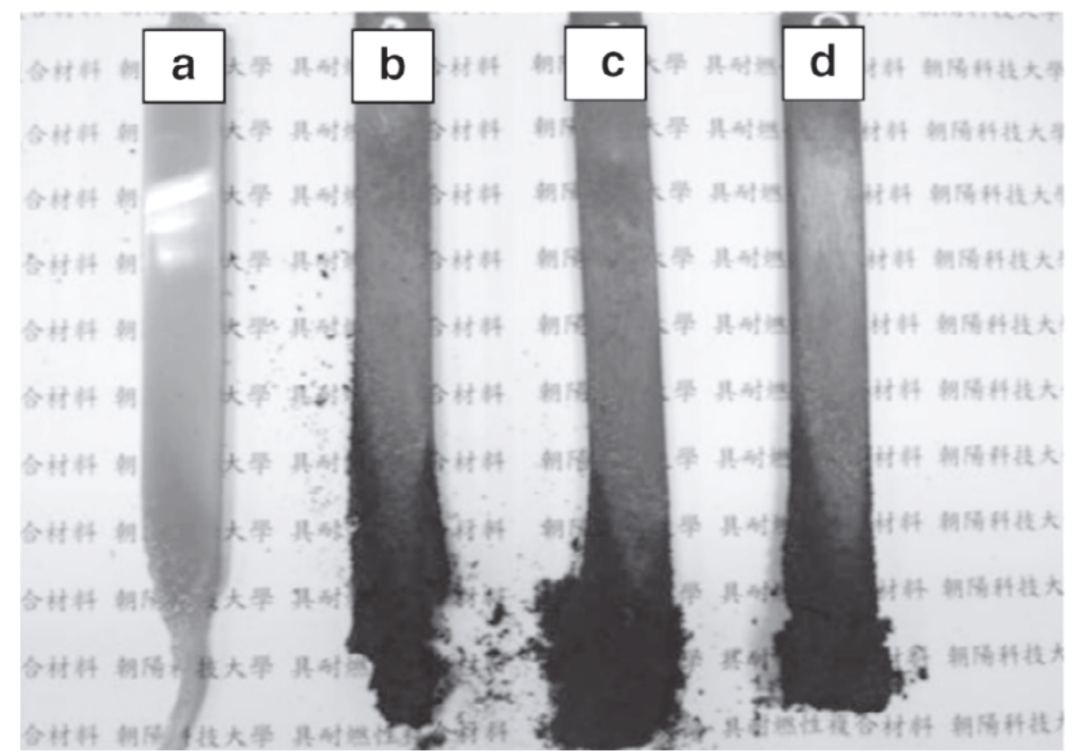

Figure 7. Photographic images of char residues after combustion of (a) neat PLA (b) PLA/13EG-4APP/MCF/MOMMT, (c) PLA/23EG-4APP/MCF/MOMMT, and (d) PLA/13EG 8APP/MCF/MOMMT composites. Reproduced from ref. [194].

The effect of MMT loading on the properties of methacrylic anhydride modified epoxidized soybean oil (MAESO), wood flour (WF) and divinyl acrylicpimaric acid (DAPA) was investigated by Mandal et al. The properties of composites with different percentages of nano-clay were investigated and reported. The composites were prepared by compression molding at loadings of $0,1,3$ and $5 \mathrm{wt} . \%$ of MMT. The flame retardance characteristic was by determined by the LOI value. Based on the result, the LOI value of the MAESO/DAPA/WF composites increased with the increase in the MMT loading. The recorded LOI value for MAESO/DAPA/WF/MMT0, MAESO/DAPA/WF/MMT1, and MAESO/DAPA/WF/MMT3 were 55\%, 57\% and $60 \%$, respectively. Beyond the $3 \mathrm{wt} . \%$ level, the LOI value decreased as observed for the MAESO/DAPA/WF/MMT5 with 58\%. Similar like the previously reported study, the MMT produced silicate char on the surface of the composites and provided a thermal barrier to the oxygen and heat. This resulted to the improvement of LOI value and the flame retardancy of the composites. However, at high MMT loading, there is a tendency of the nanoclay to agglomerate and thus decrease the interactions and barrier properties [195].

\section{Biodegradation Properties of MMT/Natural Fiber Reinforced Polymer Nanocomposites}

The incorporation of reinforcement in composite systems could enormously change the overall degradation characteristics of the resulting polymer composites systems. This is attributed to the superior properties of natural fiber reinforced polymer composites with nanoparticles due to their nano-level characteristics which maximize the interfacial adhesion. The addition of nanoclays not only can significantly improve the mechanical properties of the biocomposites, but also enhance the barrier properties and chemical hindrance, which leads to the reduction of the biodegradation time for the composites [195,196]. In addition, the incorporation of nanoparticles with antibacterial properties like those that MMTs can possibly affect the antibacterial properties of biocomposite systems by diminishing the quantity and propagation of microbes (bacteria, fungi).

The study on the effect of MMT loading in wood/plant oil composites was studied by Moon et al. [195] with a focus on the biodegradation properties of the composites. 
Composite samples were loaded with 0, 1, 3 and $5 \mathrm{wt} . \%$ of MMT and treated with a cellulolytic bacterial strain in liquid broth culture medium for the biodegradation study. In general, the addition of MMT resulted in declines in the collapse of wood composites caused by its antimicrobial activity. The weight loss of the composites was observed after 3 month of incubation. It is started with the bacterial growth of the bacterium Pseudomonas sp. that initially degraded the lignin part of the wood and continued to degrade cellulose and pectin after the production of cellulose and pectinase enzymes. Through the evaluation on the SEM results, the physical breakdown of composite on exposure to microbes were reported, attributed to the bacterial degradation activity. The degradation also shown to be prominent for a control sample without addition of MMT. The biodegradation activity was shown to decrease as the MMT loading increased due to the strong interconnected network of MMT in the composite which slowed down the accessibility and reactivity of the microorganisms. The addition of nanoclay also hinders the water absorption process thus further inhibiting the penetration of microorganisms within the composites.

Another study has been done by Islam et al. [197] to evaluate the effect of MMT addition on the biodegradability properties of kenaf/coir/PP composites. Similar findings were also reported as the biodegradability properties decrease as the MMT loading increased in the composite systems. The enhancement of the mechanical properties of the composites after the addition of MMT filler was seen to reduce the possibility of the weight loss of the composites thus diminishing the biodegradation process. These properties are very important to enhance the quality of the natural fiber-reinforced polymer composites to make them worthy materials for various applications, especially those that require strength and high durability.

\section{Applications and Potential Use of MMT/Natural Fiber Reinforced Polymer Nanocomposites}

To date, extensive studies has been conducted on lignocellulosic fiber-reinforced polymer composites hybridised with MMT nanoclays and they are growing in popularity in the development of advanced constructional and structural materials with superior performance at a low cost [34]. For instance, Islam et al. [133] revealed that after incorporating MMT, hybrid coir/wood/PP composites had higher tensile strength and modulus than wood/PP and coir/PP composites. The nanoclay improved the mechanical properties of the composites by enhancing interfacial interactions and the adhesion between the fiber and the polymer matrix. Majeed et al. [32] have studied the hybridization effect of MMT and RH on the mechanical and thermal properties of PP nanocomposites and discovered that the tensile and flexural modulus of PP increased by $63 \%$ and $92 \%$, respectively, when RH and MMT were incorporated simultaneously into the PP matrix. The authors also found that adding solely RH to the PP matrix reduced the thermal stability of the composites. However, introducing MMT to PP/RH composites enhanced the thermal stability. DSC studies demonstrated that adding RH and MMT to the PP matrix increased crystallinity while maintaining melting and crystallization temperatures. Hybrid nanotechnology brings in a new era in material science, contributing to the development of ultra-high-tech advanced composites for future engineering applications. In regards to this matter, material scientists aim to diversify the applicability of MMT/lignocellulosic fiber nanocomposites in various areas, including electronics, automotive, outdoors, and adsorbents, as discussed in the subsections that follow.

\subsection{Automotive Applications}

With significant advances in science and technology, the manufacturing industries are shifting to more sustainable and environmentally friendly economic production. In relation to this matter, researchers are focusing their attention on developing novel materials for the benefit of society. Hybridizing lignocellulosic fiber with MMT presently offers tremendous potential in terms of features that can transcend conventional composites with the inclusion of only a small amount $(5 \%)$ of nanoparticles, including superior mechanical strength, higher elastic modulus, high thermal stability, and fire resistance [198]. 
Hybridised nanocomposites have opened up new possibilities in the automotive industry due to their hassle-free fabrication and overall property improvements.

According to Galimberti et al. [199], the main driving forces for using clay polymer nanocomposites in the automotive field can be summarized as follows: (i) lighter weight of the vehicle, with fuel savings and reductions in $\mathrm{CO}_{2}$ emissions: (ii) greater safety, (iii) better drivability, and (iv) increased comfort. These aims can be achieved by introducing MMT as a nanofiller in the polymer nanocomposites of a car. The MMT nanoclay hybridised with lignocellulosic fiber-reinforced polymer composites can be applied to several parts of a car such as suspension and braking systems, engines and power train, exhaust systems and catalytic converters, frames and body parts, paints and coatings, lubrication, tires, electrical and electronic equipment. By referring to Table 11, several thermoplastic or elastomeric polymers have been used in hybridised nanocomposites containing about $80 \%$ of clay minerals [199].

Table 11. Parts of a car and polymer matrices for clay polymer nanocomposite application.

\begin{tabular}{cc}
\hline Part of Car & Polymer \\
\hline Timing belt/engine cover & Nylon-6 \\
\hline $\begin{array}{c}\text { Step-assist, doors, center bridge, sail panel, seat } \\
\text { backs and box-rail protector }\end{array}$ & PP, thermoplastic olefin \\
\hline Rear floor & Thermoset polymer matrix (with glass fiber) \\
\hline Tire & SBR \\
\hline Thread & SBR, NBR, BR \\
\hline Inner liner & Isoprene isobutylene copolymer, NBR \\
\hline Internal compounds & NBR \\
\hline
\end{tabular}

Another important feature that needs to be highlighted is the flammability properties of automotive parts. Nowadays, most parts in cars have been replaced with plastic-based materials for lighter and more fuel-efficient cars. However, for this reason, the severity of collisions and non-crash auto fires is likely to worsen. Despite the implementation of rules imposed by the Federal Motor Vehicle Safety Standard and Flammability of Interior Materials issued by the National Highway Traffic Safety Administration (NHTSA) in 1968 and 1972, respectively, by the US government, fires have continued to be a serious threat. The combustible plastics in the form of electrical wiring, upholstery, and miscellaneous components are the most likely parts to ignite in automobile fires $(47 \%)$ which is worsened by $27 \%$ by the presence of fuel for ignition. Therefore, due to the fire hazard caused by the plastic materials in motor vehicles and the speed at which plastics spread flames, smoke and combustion into the passenger compartment, automakers have continued to seek solutions to reduce the risk of fires occurring rather than relying on rescue efforts once the fire is initiated [200]. The effectiveness of nanoclay to improve the flammability properties of the lignocellulosic reinforced polymer composites was studied by Chee et al. [192] using bamboo/kenaf/epoxy nanocomposites reinforced with different types of nanoclay viz. MMT and O-MMT. Through the study, all hybrid nanocomposites achieved an HB40 rating in the UL94 horizontal burning test. However, the LOI value of the nanocomposites was observed to increase from $20 \%$ to $28 \%$ after the addition of nanoclays. The smoke generation was also remarkably reduced after the addition of nanoclays. The authors stated the mechanism of improvement imparted by the addition of nanoclays relies on the formation of an insulator barrier that provides a better charring effect which limits the migration of mass and heat between the gas and solid phase during the combustion process. The authors also found the effectiveness of organically modified MMT (O-MMT) compared to unmodified nanoclay due to better dispersion level with less agglomeration. 


\subsection{Outdoor Applications}

Composite materials are generally designed and developed for use outdoors. Various types of composite technologies have been accessible in the market over the last few decades, but not all of them are suitable for integration or incorporation in building envelopes. These materials must be able to withstand temperatures of up to $60^{\circ} \mathrm{C}$ or higher in particular to be suited for outdoor applications [201]. Moreover, composites should be able to meet certain key standards in terms of mechanical stability, fire resistance, sound insulation, thermal insulation, and other features as building components. Nevertheless, most polymers used for outdoor applications are light sensitive and frequently subjected to weathering, making them susceptible to degradation. Weathering aging, or more precisely photo-oxidation of polymer structures, is another aging mechanism that negatively impacts the service life of polymer materials under high-temperature conditions or in outdoor applications [202]. Weathering aging occurs when a polymer absorbs ultraviolet solar photons and atmospheric oxygen, resulting in discoloration and undesirable loss of mechanical properties caused by chemical bond scission and chain crosslinking of the polymer structure with exposure time [203]. Generally, weathering aging begins on the surface and eventually penetrates all the polymer material, depending on their chemical composition, environmental conditions, and exposure time [204]. However, it should be emphasized that degradation can be slowed but not totally avoided. This exposure causes catastrophic failure or severely jeopardizes the structural integrity of composite materials, diminishing their overall thermomechanical characteristics [205].

Kord et al. [206] found that exposing weathered samples (virgin polymers) for a longer time in an accelerated weathering environment elevated color change, lightness and water absorption. Hybrid nanocomposites, on the other hand, showed minor alterations in lightness and water absorption. Water cannot penetrate further into the composite because nanosized MMT could fill micro voids and fiber lumens, providing indirect weathering protection by reducing water absorption and oxidative activity, which results in less lightening [207]. Therefore, they can withstand the impacts of the sun, rain, and other weather conditions. Zahedi and his co-workers [116] observed a similar finding. The hybridization of MMT with lignocellulosic fiber also improves the nanocomposites resistance to electricity, chemicals, heat and flame, allowing these materials to be used as potential components for building enclosures including roofs, walls, windows, and shadings [51,208].

Most natural fiber reinforced composites (NFRPCs) find usage in outdoor applications, such as for construction products and building elements to comply with the fire safety codes such as EN 13501-1-2009 that emphasize fire resistance properties as necessary. Therefore, it is very important to develop and optimize fire-retardant composite materials at laboratory scale for evaluation through standard techniques such as TGA, Cone calorimetry based on ISO 5660-1 standard, limited oxygen index (LOI), burning test (UL 94 vertical or horizontal burning test) etc. [209,210]. The studies on NFRPC for outdoor applications as an alternative for conventional materials such as for components like roofs and door panels have been widely reported. Despite evaluating the mechanical and physical performance of the NFRPC, it is necessary to evaluate the flame and thermal resistance of the fabricated composite in case of any fire accidents. Through a series of laboratory analyses, Rajini et al. [211] proved the improvement in the thermal and flammability properties of the coconut sheath (CS) reinforced PE composite. The hybridization of the CS/PE composite with $5 \mathrm{wt} . \%$ of MMT nanoclay was observed to remarkably decrease the heat release rate and the mass loss rate of the composites by the char formation mechanism. The char formation acted as a heat barrier, thus lowered the flammability properties of the composites. Moreover, treated CS fiber also influenced the thermal properties of the composites by lowering the degradation temperature due to the presence of more hydroxyl group to attract water. This finding proved the ability of hybrid lignocellulosic/MMT polymer composites to be applied for outdoor applications. 


\subsection{Coating Applications}

The integration of filler such as nanoclays, cellulose micro- or nanofibers, and MMT into coating products is generating a lot of attention in terms of improving general physical characteristics in plastics and bioplastics. The use of cellulose biofibers in melt blending and solution casting processing methods to enhance the barrier characteristics to gases and vapors and to impart new functions to biopackaging plastics has resulted in the creation of nanocomposites for food packaging applications. It has also been found that reinforcing biopolymers with organically modified MMT improves their characteristics significantly. MMT have been used as possible packaging materials in many studies. Chowdhury [212] investigated the effect of adding mica nanoclay to a PLA matrix vs. using MMT nanoclay and found that the oxygen barrier was improved. Mohan and Kanny [213] in their study was found that the MMT-treated fibers have a higher surface area, resulting in less moisture absorption. They also found that untreated and MMT-treated fibers have sigmoidal isotherm sorption behaviour, and sorption hysteresis is dependent on crystallinity and MMT infusion.

\section{Environmental Concerns, Health, and Safety Issues of MMT}

The inclusion of MMT into polymeric systems improves their barrier, thermal, and mechanical resistance, making them ideal for a multitude of industrial applications, including environmental remediation, engineering and construction, and food industry. Moreover, MMT has been widely utilized for biological applications since it has demonstrated very low cytotoxicity both in vitro and in vivo, and owing to its chemical properties, MMT can intercalate biologically active molecules, resulting in efficient systems for oral or topical drug delivery [214]. Nevertheless, MMT extraction, development, and application, like most other materials, are prone to environmental and safety concerns.

There have been relatively few experimental investigations into the exposure and possible toxicity of MMT to living organisms up to this moment. Even so, there are possibly two key aspects that should be considered when utilizing MMT: particle size and chemical composition. Epidemiological research has shown that morbidity and fatality have been related to an elevation in airborne particles, primarily those within the ultrafine size range $(<0.1 \mu \mathrm{m})[51]$. These nanoparticles have the tendency to penetrate the human body and circulate via the bloodstream to vital organs, causing toxicity and health issues such as tissue damage. Based on the findings of Mainasaba et al. [215], it can be inferred that MMT is potentially genotoxic since it induces the formation of micronuclei at non-cytotoxic concentrations, and thus poses a threat to human health, particularly when long-term exposure is considered. Nonetheless, MMT incorporated into bulk materials or polymer products will not cause these problems.

Till now, there seem to be no experimental investigations into MMT exposure in natural environments and its potential toxicity. There is virtually no known information regarding the exposure pathways, the limits of MMT exposure, and their toxicity towards the environment in occupation-related scenarios all over the world since this data has not been reported elsewhere. To monitor nanosafety for the environment in the real world, environmentally aware product design frameworks and life cycle assessment (LCA) approaches are recommended. The most essential steps in characterizing and evaluating MMT in the environment are the development of MMT databases to analyze the LCA of products: gathering real MMT data for the development of exposure limits for MMT and formulation of advanced models, as well as the implementation of standardized protocols [216]. These procedures will aid in determining the risks associated with the application of MMT in the real world, therefore improving worker safety.

\section{Conclusions and Future Outlook}

The implementation of MMT to modify composites for structural applications is gradually expanding. The inclusion of the nanofillers not only takes place in pure polymer and synthetic fiber reinforced polymer composites, but moreover in biocomposites which 
are mainly made up of lignocellulosic fibers. Most research studies found that the introduction of MMT enhanced the mechanical and water barrier properties of biocomposites as well as their thermal capability. These behaviour alterations depend mainly on the exfoliated/intercalated balance of the nanoclay filler introduced. The review article also specifies that flexural, tensile, compression, and impact strength were investigated for a wide range of solutions and uses.

According to the literature, MMT can be a well dispersed in polymer resins with the aid of mechanical stirrers to improve its homogeneity. Compared with the pure polymer matrix, the addition of the MMT in composites results in low dielectric permittivity, low dielectric loss, and enhanced dielectric strength. Moreover, the MMT nanofillers allow the enhancement in terms of thermal conductivity and stability. These improvement properties are highly influenced by the compatibility of interfaces between MMT and polymer resin. Other than that, the MMT modified with chemical treatments such as GPTMS and gAPTES promote greater influence in improving the interface between the nanoparticles and polymer matrices, thus causing lower dielectric loss, electric conductivity, lower thermal conductivity, as well as higher thermal stability and breakdown strength. From this point of view, it can be concluded that the inclusion of MMT could potentially benefit the structural industries, especially in the electrical transmission sector, since it promotes good electrical insulation properties in composites. In conclusion, this review can benefit many composite structural sectors in order to stimulate lower raw material and manufacturing costs of composite products with great strength and stiffness.

Author Contributions: Conceptualization, M.N.N. and A.R.I.; validation, M.N.N., A.R.I. and A.K.; writing-original draft preparation, A.H.A., M.N.N., F.A.S., M.R.M.A., M.N.F.N., A.R.I., A.M.K., M.R., S.S.S., A.N., S.F.K.S., M.M.H. and M.S.N.A.; supervision, M.R.I., S.M.S. and A.K.; project administration, A.H.A.; funding acquisition, A.K. All authors have read and agreed to the published version of the manuscript.

Funding: This research was funded by Higher Education Center of Excellence (HICoE), Ministry of Higher Education, Malaysia (Grant number 6369109).

Institutional Review Board Statement: Not applicable.

Informed Consent Statement: Not applicable.

Data Availability Statement: Not applicable.

Acknowledgments: The authors gratefully acknowledge the technical and financial support from the Universiti Putra Malaysia (UPM).

Conflicts of Interest: The authors declare no conflict of interest.

\section{Abbreviations}

The following abbreviations are used in this manuscript:

$\begin{array}{ll}\text { APTES } & \text { Aminopropyltriethoxysilane } \\ \text { APP } & \text { Ammonium polyphosphate (APP) } \\ \text { B } & \text { Bamboo } \\ \text { BR } & \text { Butadiene rubber } \\ \text { CF } & \text { Chopstick fiber } \\ \text { CNF } & \text { Cellulose nanofibers } \\ \text { CNW } & \text { Cellulose nanowhiskers } \\ \text { COP } & \text { Carbon monoxide production } \\ \text { CS } & \text { Coconut sheath } \\ \text { CS } & \text { Corn starch }\end{array}$




\begin{tabular}{|c|c|}
\hline DAPA & Divinyl acrylicpimaric acid \\
\hline DMA & Dynamic mechanical analysis \\
\hline DSC & Differential scanning calorimetry \\
\hline DTG & Derivative thermogravimetry \\
\hline$E^{\prime \prime}$ & Loss modulus \\
\hline$E^{\prime}$ & Storage modulus \\
\hline ECAE & Equal channel angular extrusion \\
\hline $\mathrm{EP}$ & Ethylene-propylene \\
\hline EVA & Ethylene-vinyl acetate \\
\hline $\mathrm{EVOH}$ & Ethylene vinyl alcohol \\
\hline EG & Expandable graphene \\
\hline GPTMS & Glicydoxy propyl trimethoxysilane \\
\hline HDPE & High density polyethylene \\
\hline HDT & Heat deflection temperature \\
\hline HNT & Halloysite nanotube \\
\hline HRR & Heat release rate \\
\hline iPP & isotactic PP \\
\hline IFR & Intumescent flame retardant \\
\hline K & Kenaf \\
\hline $\mathrm{KeC}$ & Kenaf composites \\
\hline KF & Kenaf fiber \\
\hline LCA & Life cycle assessment \\
\hline LDPE & Low-density polyethylene \\
\hline LOI & Limiting oxygen index \\
\hline MAESO & Methacrylic anhydride modified epoxidized soybean oil \\
\hline MAH & Maleic anhydride \\
\hline $\mathrm{MaPE}$ & Maleic anhydride-grafted polyethylene \\
\hline MAPP & Maleated anhydride grafted polypropylene \\
\hline MCC & Microcrystalline cellulose \\
\hline MCF & Modified chopstick fiber \\
\hline MEP & Maleated ethylene-propylene \\
\hline MLR & Mass loss rate \\
\hline MMT & Montmorillonite \\
\hline MOMMT & Modified montmorillonite \\
\hline NaMMT & natural sodium montmorillonite \\
\hline NBR & Nitrile butadiene rubber \\
\hline NFRPC & Natural fiber reinforced composites \\
\hline NHTSA & National highway traffic safety administration \\
\hline OMLS & Organo-modified layered silicates \\
\hline OMMT & Organically modified montmorillonite \\
\hline OPEFB & Oil palm empty fruit bunch \\
\hline OTR & Oxygen transmission rate \\
\hline PBS & Poly(butylene succinate \\
\hline PEG & Poly(ethylene glycol) \\
\hline PEMA & Poly(ethylmethacrylate) \\
\hline PEO & Poly(ethylene oxide) \\
\hline PHR & Peak of release heat \\
\hline PLA & Polylactic acid \\
\hline PP-g-MAH & Maleic anhydride grafted polypropylene \\
\hline $\mathrm{PP}$ & Polypropylene \\
\hline PS & Polystyrene \\
\hline PVA & Polyvinyl alcohol \\
\hline PVC & Poly(vinylchloride) \\
\hline PVP & Poly(vinyl pyrrolidone) \\
\hline $\mathrm{RH}$ & Rice husk \\
\hline SBR & Styrene butadiene rubber \\
\hline $\mathrm{SiB}$ & Silane treated banana fiber \\
\hline
\end{tabular}




$\begin{array}{ll}\text { SPR } & \text { Smoke release } \\ \text { SEM } & \text { Scanning electron microscope } \\ \text { TAF } & \text { Treated aloe vera fiber } \\ \text { TEM } & \text { Transmission electron microscopy } \\ \text { TKF } & \text { Treated kenaf fiber } \\ \text { TG } & \text { Thermogravimetry } \\ \text { TGA } & \text { Thermogravimetric analysis } \\ \text { THR } & \text { Total heat release } \\ \text { TPS } & \text { Tapioca starch } \\ \text { TTI } & \text { Time to ignition } \\ \text { WF } & \text { Wood flour } \\ \text { WHF } & \text { Water hyacinth fiber } \\ \text { WSF } & \text { Walnut shell flour } \\ \text { WVTR } & \text { Water vapour permeability rate }\end{array}$

\section{References}

1. Asyraf, M.R.M.; Ishak, M.R.; Sapuan, S.M.; Yidris, N. Utilization of Bracing Arms as Additional Reinforcement in Pultruded Glass Fiber-Reinforced Polymer Composite Cross-Arms: Creep Experimental and Numerical Analyses. Polymers 2021, 13, 620. [CrossRef] [PubMed]

2. Ogin, S.L.; Brøndsted, P.; Zangenberg, J. Composite Materials: Constituents, Architecture, and Generic Damage; Elsevier: Amsterdam, The Netherlands, 2016.

3. Nurazzi, N.M.; Asyraf, M.R.M.; Khalina, A.; Abdullah, N.; Aisyah, H.A.; Rafiqah, S.A.; Sabaruddin, F.A.; Kamarudin, S.H.; Norrahim, M.N.F.; Ilyas, R.A.; et al. A Review on Natural Fiber Reinforced Polymer Composite for Bullet Proof and Ballistic Applications. Polymers 2021, 13, 646. [CrossRef]

4. Asyraf, M.R.M.; Ishak, M.R.; Sapuan, S.M.; Yidris, N. Influence of Additional Bracing Arms as Reinforcement Members in Wooden Timber Cross-Arms on Their Long-Term Creep Responses and Properties. Appl. Sci. 2021, 11, 2061. [CrossRef]

5. Amir, A.L.; Ishak, M.R.; Yidris, N.; Zuhri, M.Y.M.; Asyraf, M.R.M. Advances of composite cross arms with incorporation of material core structures: Manufacturability, recent progress and views. J. Mater. Res. Technol. 2021, 13, 1115-1131. [CrossRef]

6. Asyraf, M.R.M.; Ishak, M.R.; Sapuan, S.M.; Yidris, N.; Ilyas, R.A. Woods and composites cantilever beam: A comprehensive review of experimental and numerical creep methodologies. J. Mater. Res. Technol. 2020, 9, 6759-6776. [CrossRef]

7. Asyraf, M.R.M.; Ishak, M.R.; Sapuan, S.M.; Yidris, N. Comparison of Static and Long-term Creep Behaviors between Balau Wood and Glass Fiber Reinforced Polymer Composite for Cross-arm Application. Fibers Polym. 2021, 22, 793-803. [CrossRef]

8. Ilyas, R.A.; Sapuan, S.M.; Harussani, M.M.; Hakimi, M.Y.A.Y.; Haziq, M.Z.M.; Atikah, M.S.N.; Asyraf, M.R.M.; Ishak, M.R.; Razman, M.R.; Nurazzi, N.M.; et al. Polylactic Acid (PLA) Biocomposite: Processing, Additive Manufacturing and Advanced Applications. Polymers 2021, 13, 1326. [CrossRef]

9. Kyriazoglou, C.; Guild, F.J. Quantifying the effect of homogeneous and localized damage mechanisms on the damping properties of damaged GFRP and CFRP continuous and woven composite laminates-an FEA approach. Compos. Part A Appl. Sci. Manuf. 2005, 36, 367-379. [CrossRef]

10. Hamidon, M.H.; Sultan, M.T.H.; Ariffin, A.H.; Shah, A.U.M. Effects of fibre treatment on mechanical properties of kenaf fibre reinforced composites: A review. J. Mater. Res. Technol. 2019, 8, 3327-3337. [CrossRef]

11. Ali, S.S.S.; Razman, M.R.; Awang, A.; Asyraf, M.R.M.; Ishak, M.R.; Ilyas, R.A.; Lawrence, R.J. Critical Determinants of Household Electricity Consumption in a Rapidly Growing City. Sustainability 2021, 13, 4441. [CrossRef]

12. Ilyas, R.A.; Sapuan, S.M.; Atiqah, A.; Ibrahim, R.; Abral, H.; Ishak, M.R.; Zainudin, E.S.; Nurazzi, N.M.; Atikah, M.S.N.; Ansari, M.N.M.; et al. Sugar palm (Arenga pinnata [Wurmb.] Merr) starch films containing sugar palm nanofibrillated cellulose as reinforcement: Water barrier properties. Polym. Compos. 2020, 41, 459-467. [CrossRef]

13. Ilyas, R.; Sapuan, S.; Atikah, M.; Asyraf, M.; Rafiqah, S.A.; Aisyah, H.; Nurazzi, N.M.; Norrrahim, M. Effect of hydrolysis time on the morphological, physical, chemical, and thermal behavior of sugar palm nanocrystalline cellulose (Arenga pinnata (Wurmb.) Merr). Text. Res. J. 2021, 91, 152-167. [CrossRef]

14. Omran, A.A.B.; Mohammed, A.A.B.A.; Sapuan, S.M.; Ilyas, R.A.; Asyraf, M.R.M.; Koloor, S.S.R.; Petrů, M. Micro- and Nanocellulose in Polymer Composite Materials: A Review. Polymers 2021, 13, 231. [CrossRef]

15. Alsubari, S.; Zuhri, M.Y.M.; Sapuan, S.M.; Ishak, M.R.; Ilyas, R.A.; Asyraf, M.R.M. Potential of Natural Fiber Reinforced Polymer Composites in Sandwich Structures: A Review on Its Mechanical Properties. Polymers 2021, 13, 423. [CrossRef]

16. Ilyas, R.A.; Sapuan, S.M.; Asyraf, M.R.M.; Atikah, M.S.N.; Ibrahim, R.; Dele-Afolabia, T.T. Introduction to biofiller reinforced degradable polymer composites. In Biofiller Reinforced Biodegradable Polymer Composites; Sapuan, S.M., Jumaidin, R., Hanafi, I., Eds.; CRC Press: Boca Raton, FL, USA, 2020; pp. 1-23.

17. Nurazzi, N.M.; Asyraf, M.R.M.; Khalina, A.; Abdullah, N.; Sabaruddin, F.A.; Kamarudin, S.H.; Ahmad, S.; Mahat, A.M.; Lee, C.L.; Aisyah, H.A.; et al. Fabrication, functionalization, and application of carbon nanotube-reinforced polymer composite: An overview. Polymers 2021, 13, 1047. [CrossRef] 
18. Asyraf, M.R.M.; Rafidah, M.; Azrina, A.; Razman, M.R. Dynamic mechanical behaviour of kenaf cellulosic fibre biocomposites: A comprehensive review on chemical treatments. Cellulose 2021, 28, 2675-2695. [CrossRef]

19. Amir, A.L.; Ishak, M.R.; Yidris, N.; Zuhri, M.Y.M.; Asyraf, M.R.M. Potential of Honeycomb-Filled Composite Structure in Composite Cross-Arm Component: A Review on Recent Progress and Its Mechanical Properties. Polymers 2021, $13,1341$. [CrossRef]

20. Johari, A.N.; Ishak, M.R.; Leman, Z.; Yusoff, M.Z.M.; Asyraf, M.R.M. Influence of CaCO3 in pultruded glass fibre/unsaturated polyester composite on flexural creep behaviour using conventional and TTSP methods. Polimery 2020, 65, 46-54. [CrossRef]

21. El-zayat, M.M.; Mohamed, M.A. Effect of gamma radiation on the physico mechanical properties of recycled HDPE/modified sugarcane bagasse composite. J. Macromol. Sci. Part A 2019, 56, 1-9. [CrossRef]

22. Nurazzi, N.M.; Harussani, M.M.; Aisyah, H.A.; Ilyas, R.A.; Norrrahim, M.N.F.; Khalina, A.; Abdullah, N. Treatments of natural fiber as reinforcement in polymer composites-a short review. Funct. Compos. Struct. 2021, 3, 024002. [CrossRef]

23. Zin, M.H.; Abdan, K.; Norizan, M.N.; Mazlan, N. The effects of alkali treatment on the mechanical and chemical properties of banana fibre and adhesion to epoxy resin. Pertanika J. Sci. Technol. 2018, 26, 161-176.

24. Norizan, M.N.; Abdan, K.; Salit, M.S.; Mohamed, R. The effect of alkaline treatment on the mechanical properties of treated sugar palm yarn fibre reinforced unsaturated polyester composites reinforced with different fibre loadings of sugar palm fibre. Sains Malaysiana 2018, 47, 699-705. [CrossRef]

25. Abdel-Hakim, A.; El-Wakil, A.E.A.A.; El-Mogy, S.; Halim, S. Effect of fiber coating on the mechanical performance, water absorption and biodegradability of sisal fiber/natural rubber composite. Polym. Int. 2021, 70, 1356-1366. [CrossRef]

26. Abdel-Hakim, A.; Mourad, R.M. Mechanical, water uptake properties, and biodegradability of polystyrene-coated sisal fiberreinforced high-density polyethylene. Polym. Compos. 2020, 41, 1435-1446. [CrossRef]

27. Akil, H.M.; Santulli, C.; Sarasini, F.; Tirillò, J.; Valente, T. Environmental effects on the mechanical behaviour of pultruded jute/glass fibre-reinforced polyester hybrid composites. Compos. Sci. Technol. 2014, 94, 62-70. [CrossRef]

28. Ilyas, R.A.; Sapuan, S.M.; Asyraf, M.R.M.; Dayana, D.A.Z.N.; Amelia, J.J.N.; Rani, M.S.A.; Norrrahim, M.N.F.; Nurazzi, N.M.; Aisyah, H.A.; Sharma, S.; et al. Polymer composites filled with metal derivatives: A review of flame retardants. Polymers 2021, 13, 1701. [CrossRef]

29. Azman, M.A.; Asyraf, M.R.M.; Khalina, A.; Petrů, M.; Ruzaidi, C.M.; Sapuan, S.M.; Wan Nik, W.B.; Ishak, M.R.; Ilyas, R.A.; Suriani, M.J. Natural Fiber Reinforced Composite Material for Product Design: A Short Review. Polymers 2021, 13, 1917. [CrossRef]

30. Edwards, D.C. Polymer-filler interactions in rubber reinforcement. J. Mater. Sci. 1990, 25, 4175-4185. [CrossRef]

31. Bhattacharya, M. Polymer Nanocomposites-A Comparison between Carbon Nanotubes, Graphene, and Clay as Nanofillers. Materials 2016, 9, 262. [CrossRef]

32. Majeed, K.; Ahmed, A.; Abu Bakar, M.S.; Mahlia, T.M.I.; Saba, N.; Hassan, A.; Jawaid, M.; Hussain, M.; Iqbal, J.; Ali, Z. Mechanical and thermal properties of montmorillonite-reinforced polypropylene/rice husk hybrid nanocomposites. Polymers 2019, $11,1557$. [CrossRef]

33. Okada, A.; Usuki, A. Twenty years of polymer-clay nanocomposites. Macromol. Mater. Eng. 2006, 291, 1449-1476. [CrossRef]

34. Ramesh, P.; Prasad, B.D.; Narayana, K.L. Effect of fiber hybridization and montmorillonite clay on properties of treated kenaf/aloe vera fiber reinforced PLA hybrid nanobiocomposite. Cellulose 2020, 27, 6977-6993. [CrossRef]

35. Khan, A.; Asiri, A.M.; Jawaid, M.; Saba, N. Inamuddin Effect of cellulose nano fibers and nano clays on the mechanical, morphological, thermal and dynamic mechanical performance of kenaf/epoxy composites. Carbohydr. Polym. 2020, 239, 116248. [CrossRef] [PubMed]

36. Shahroze, R.M.; Ishak, M.R.; Salit, M.S.; Leman, Z.; Asim, M.; Chandrasekar, M. Effect of organo-modified nanoclay on the mechanical properties of sugar palm fiber-reinforced polyester composites. BioResources 2018, 13, 7430-7444. [CrossRef]

37. Al-Samhan, M.; Samuel, J.; Al-Attar, F.; Abraham, G. Comparative Effects of MMT Clay Modified with Two Different Cationic Surfactants on the Thermal and Rheological Properties of Polypropylene Nanocomposites. Int. J. Polym. Sci. 2017, 2017, 5717968. [CrossRef]

38. Jia, Z.R.; Gao, Z.G.; Lan, D.; Cheng, Y.H.; Wu, G.L.; Wu, H.J. Effects of filler loading and surface modification on electrical and thermal properties of epoxy/montmorillonite composite. Chinese Phys. B 2018, 27, 117806. [CrossRef]

39. Ramesh, P.; Prasad, B.D.; Narayana, K.L. Effect of MMT Clay on Mechanical, Thermal and Barrier Properties of Treated Aloevera Fiber/ PLA-Hybrid Biocomposites. Silicon 2020, 12, 1751-1760. [CrossRef]

40. Rozman, H.D.; Musa, L.; Azniwati, A.A.; Rozyanty, A.R. Tensile properties of kenaf/unsaturated polyester composites filled with a montmorillonite filler. J. Appl. Polym. Sci. 2011, 119, 2549-2553. [CrossRef]

41. Asyraf, M.R.M.; Ishak, M.R.; Sapuan, S.M.; Yidris, N.; Rafidah, M.; Ilyas, R.A.; Razman, M.R. Potential application of green composites for cross arm component in transmission tower: A brief review. Int. J. Polym. Sci. 2020, 2020, 8878300. [CrossRef]

42. Nik Baihaqi, N.M.Z.; Khalina, A.; Mohd Nurazzi, N.; Aisyah, H.A.; Sapuan, S.M.; Ilyas, R.A. Effect of fiber content and their hybridization on bending and torsional strength of hybrid epoxy composites reinforced with carbon and sugar palm fibers. Polimery/Polymers 2021, 66, 36-43. [CrossRef]

43. Norrrahim, M.N.F.; Nurazzi, N.M.; Jenol, M.A.; Farid, M.A.A.; Janudin, N.; Ujang, F.A.; Yasim-Anuar, T.A.T.; Syed Najmuddin, S.U.F.; Ilyas, R.A. Emerging development of nanocellulose as an antimicrobial material: An overview. Mater. Adv. 2021, 2, 3538-3551. [CrossRef] 
44. Sabaruddin, F.A.; Paridah, M.T.; Sapuan, S.M.; Ilyas, R.A.; Lee, S.H.; Abdan, K.; Mazlan, N.; Roseley, A.S.M.; Abdul Khalil, H.P.S. The Effects of Unbleached and Bleached Nanocellulose on the Thermal and Flammability of Polypropylene-Reinforced Kenaf Core Hybrid Polymer Bionanocomposites. Polymers 2020, 13, 116. [CrossRef]

45. Ilyas, R.A.; Sapuan, M.S.; Norizan, M.N.; Norrrahim, M.N.F.; Ibrahim, R.; Atikah, M.S.N.; Huzaifah, M.R.M.; Radzi, A.M.; Izwan, S.; Azammi, A.M.N.; et al. Macro to nanoscale natural fiber composites for automotive components: Research, development, and application. In Biocomposite and Synthetic Composites for Automotive Applications; Sapuan, M.S., Ilyas, R.A., Eds.; Woodhead Publishing Series: Amsterdam, The Netherlands, 2020.

46. Zin, M.H.; Abdan, K.; Mazlan, N.; Zainudin, E.S.; Liew, K.E.; Norizan, M.N. Automated spray up process for Pineapple Leaf Fibre hybrid biocomposites. Compos. Part B Eng. 2019, 177, 107306. [CrossRef]

47. Bergaya, F.; Detellier, C.; Lambert, J.-F.; Lagaly, G. Introduction to clay-polymer nanocomposites (CPN). In Developments in Clay Science; Elsevier: Amsterdam, The Netherlands, 2013; pp. 655-677.

48. Said, M.; Abu Hasan, H.; Mohd Nor, M.T.; Mohammad, A.W. Removal of COD, TSS and colour from palm oil mill effluent (POME) using montmorillonite. Desalin. Water Treat. 2016, 57, 10490-10497. [CrossRef]

49. Uddin, F. Clays, nanoclays, and montmorillonite minerals. Metall. Mater. Trans. A 2008, 39, 2804-2814. [CrossRef]

50. Nakato, T.; Miyamoto, N. Liquid crystalline behavior and related properties of colloidal systems of inorganic oxide nanosheets. Materials 2009, 2, 1734-1761. [CrossRef]

51. Uddin, F. Montmorillonite: An introduction to properties and utilization; IntechOpen: London, UK, 2018.

52. Zhu, T.T.; Zhou, C.H.; Kabwe, F.B.; Wu, Q.Q.; Li, C.S.; Zhang, J.R. Exfoliation of montmorillonite and related properties of clay/polymer nanocomposites. Appl. Clay Sci. 2019, 169, 48-66. [CrossRef]

53. Zhou, C.H.; Keeling, J. Fundamental and applied research on clay minerals: From climate and environment to nanotechnology. Appl. Clay Sci. 2013, 74, 3-9. [CrossRef]

54. Chan, M.; Lau, K.; Wong, T.; Ho, M.; Hui, D. Mechanism of reinforcement in a nanoclay/polymer composite. Compos. Part B Eng. 2011, 42, 1708-1712. [CrossRef]

55. Zhu, B.; Wang, Y.; Liu, H.; Ying, J.; Liu, C.; Shen, C. Effects of interface interaction and microphase dispersion on the mechanical properties of PCL/PLA/MMT nanocomposites visualized by nanomechanical mapping. Compos. Sci. Technol. 2020, 190, 108048. [CrossRef]

56. Shehap, A.M.; Nasr, R.A.; Mahfouz, M.A.; Ismail, A.M. Preparation and characterizations of high doping chitosan/MMT nanocomposites films for removing iron from ground water. J. Environ. Chem. Eng. 2021, 9, 104700. [CrossRef]

57. Zare, Y.; Rhee, K.Y.; Park, S.-J. A modeling methodology to investigate the effect of interfacial adhesion on the yield strength of MMT reinforced nanocomposites. J. Ind. Eng. Chem. 2019, 69, 331-337. [CrossRef]

58. Harussani, M.M.; Sapuan, S.M.; Rashid, U.; Khalina, A. Development and Characterization of Polypropylene Waste from Personal Protective Equipment (PPE)-Derived Char-Filled Sugar Palm Starch Biocomposite Briquettes. Polymers 2021, 13, 1707. [CrossRef] [PubMed]

59. Saba, N.; Paridah, T.M.; Abdan, K.; Ibrahim, N.A. Preparation and characterization of fire retardant nano-filler from oil palm empty fruit bunch fibers. BioResources 2015, 10, 4530-4543. [CrossRef]

60. Kumar, P.; Sandeep, K.P.; Alavi, S.; Truong, V.D.; Gorga, R.E. Effect of type and content of modified montmorillonite on the structure and properties of bio-nanocomposite films based on soy protein isolate and montmorillonite. J. Food Sci. 2010, 75, N46-N56. [CrossRef]

61. Fan, Q.; Han, G.; Cheng, W.; Tian, H.; Wang, D.; Xuan, L. Effect of intercalation structure of organo-modified montmorillonite/polylactic acid on wheat straw fiber/polylactic acid composites. Polymers 2018, 10, 896. [CrossRef]

62. Xue, M.-L.; Yu, Y.-L.; Li, P. Preparation, dispersion, and crystallization of the poly (trimethylene terephthalate)/organically modified montmorillonite (PTT/MMT) nanocomposites. J. Macromol. Sci. Part B Phys. 2010, 49, 1105-1116. [CrossRef]

63. Swearingen, C.; Macha, S.; Fitch, A. Leashed ferrocenes at clay surfaces: Potential applications for environmental catalysis. J. Mol. Catal. A Chem. 2003, 199, 149-160. [CrossRef]

64. Jia, F.; Song, S. Exfoliation and characterization of layered silicate minerals: A review. Surf. Rev. Lett. 2014, 21, 1430001. [CrossRef]

65. Asgari, M.; Abouelmagd, A.; Sundararaj, U. Silane functionalization of sodium montmorillonite nanoclay and its effect on rheological and mechanical properties of HDPE/clay nanocomposites. Appl. Clay Sci. 2017, 146, 439-448. [CrossRef]

66. Nistor, M.-T.; Vasile, C. Influence of the nanoparticle type on the thermal decomposition of the green starch/poly (vinyl alcohol)/montmorillonite nanocomposites. J. Therm. Anal. Calorim. 2013, 111, 1903-1919. [CrossRef]

67. Ejder-Korucu, M.; Gürses, A.; Karaca, S. Poly (ethylene oxide)/clay nanaocomposites: Thermal and mechanical properties. Appl. Surf. Sci. 2016, 378, 1-7. [CrossRef]

68. Yang, F.; Mubarak, C.; Keiegel, R.; Kannan, R.M. Supercritical carbon dioxide (scCO2) dispersion of poly (ethylene terephthalate)/clay nanocomposites: Structural, mechanical, thermal, and barrier properties. J. Appl. Polym. Sci. 2017, 134. [CrossRef]

69. Ammar, A.; Elzatahry, A.; Al-Maadeed, M.; Alenizi, A.M.; Huq, A.F.; Karim, A. Nanoclay compatibilization of phase separated polysulfone/polyimide films for oxygen barrier. Appl. Clay Sci. 2017, 137, 123-134. [CrossRef]

70. Wu, H.; Krifa, M.; Koo, J.H. Flame retardant polyamide 6/nanoclay/intumescent nanocomposite fibers through electrospinning. Text. Res. J. 2014, 84, 1106-1118. [CrossRef]

71. Roghani-Mamaqani, H.; Haddadi-Asl, V.; Najafi, M.; Salami-Kalajahi, M. Preparation of nanoclay-dispersed polystyrene nanofibers via atom transfer radical polymerization and electrospinning. J. Appl. Polym. Sci. 2011, 120, 1431-1438. [CrossRef] 
72. Zhang, G.; Ke, Y.; He, J.; Qin, M.; Shen, H.; Lu, S.; Xu, J. Effects of organo-modified montmorillonite on the tribology performance of bismaleimide-based nanocomposites. Mater. Des. 2015, 86, 138-145. [CrossRef]

73. Kord, B. Nanofiller reinforcement effects on the thermal, dynamic mechanical, and morphological behavior of HDPE/rice husk flour composites. BioResources 2011, 6, 1351-1358.

74. Kord, B. Effect of nanoparticles loading on properties of polymeric composite based on hemp fiber/polypropylene. J. Thermoplast. Compos. Mater. 2012, 25, 793-806. [CrossRef]

75. Sinha Ray, S. Clay-Containing Polymer Nanocomposites; Elsevier: Amsterdam, The Netherlands, 2013.

76. Kenned, J.J.; Sankaranarayanasamy, K.; Kumar, C.S. Chemical, biological, and nanoclay treatments for natural plant fiberreinforced polymer composites: A review. Polym. Polym. Compos. 2020, 29. [CrossRef]

77. Norrahim, M.N.F.; Ariffin, H.; Yasim-Anuar, T.A.T.; Hassan, M.A.; Ibrahim, N.A.; Yunus, W.M.Z.W.; Nishida, H. Performance Evaluation of Cellulose Nanofiber with Residual Hemicellulose as a Nanofiller in Polypropylene-Based Nanocomposite. Polymers 2021, 13, 1064. [CrossRef]

78. Norrahim, M.N.F.; Ariffin, H.; Yasim-Anuar, T.A.T.; Ghaemi, F.; Hassan, M.A.; Ibrahim, N.A.; Ngee, J.L.H.; Yunus, W.M.Z.W. Superheated steam pretreatment of cellulose affects its electrospinnability for microfibrillated cellulose production. Cellulose 2018, 25, 3853-3859. [CrossRef]

79. Norrrahim, M.N.F.; Ariffin, H.; Hassan, M.A.; Ibrahim, N.A.; Yunus, W.M.Z.W.; Nishida, H. Utilisation of superheated steam in oil palm biomass pretreatment process for reduced chemical use and enhanced cellulose nanofibre production. Int. J. Nanotechnol. 2019, 16, 668-679. [CrossRef]

80. Matsuda, D.K.M.; Verceheze, A.E.S.; Carvalho, G.M.; Yamashita, F.; Mali, S. Baked foams of cassava starch and organically modified nanoclays. Ind. Crops Prod. 2013, 44, 705-711. [CrossRef]

81. Andlar, M.; Rezić, T.; Marđetko, N.; Kracher, D.; Ludwig, R.; Šantek, B. Lignocellulose degradation: An overview of fungi and fungal enzymes involved in lignocellulose degradation. Eng. Life Sci. 2018, 18, 768-778. [CrossRef]

82. Mohammed, L.; Ansari, M.N.; Pua, G.; Jawaid, M.; Islam, M.S. A review on natural fiber reinforced polymer composite and its applications. Int. J. Polym. Sci. 2015, 2015, 243947. [CrossRef]

83. Komuraiah, A.; Kumar, N.S.; Prasad, B.D. Chemical composition of natural fibers and its influence on their mechanical properties. Mech. Compos. Mater. 2014, 50, 359-376. [CrossRef]

84. Nurazzi, N.M.; Khalina, A.; Sapuan, S.M.; Ilyas, R.A.; Rafiqah, S.A.; Hanafee, Z.M. Thermal properties of treated sugar palm yarn/glass fiber reinforced unsaturated polyester hybrid composites. J. Mater. Res. Technol. 2020, 9, 1606-1618. [CrossRef]

85. Rahul, K.C. Chemical Analysis of Spruce Needles. Available online: https://www.theseus.fi/handle/10024/280086 (accessed on 20 May 2021).

86. Brunner, G. Processing of biomass with hydrothermal and supercritical water. In Supercritical Fluid Science and Technology; Elsevier: Amsterdam, The Netherlands, 2014; pp. 395-509.

87. Malherbe, S.; Cloete, T.E. Lignocellulose biodegradation: Fundamentals and applications. Rev. Environ. Sci. Biotechnol. 2002, 1, 105-114. [CrossRef]

88. Mohanty, A.K.; Misra, M.; Hinrichsen, G. Biofibres, biodegradable polymers and biocomposites: An overview. Macromol. Mater. Eng. 2000, 24, 1-24. [CrossRef]

89. Patel, J.P. and Parsania, P.H. Characterization, testing, and reinforcing materials of biodegradable composites. In Biodegradable and Biocompatible Polymer Composites; Elsevier: Amsterdam, The Netherlands, 2018; pp. 55-79.

90. Calvo-Flores, F.G.; Dobado, J.A. Lignin as renewable raw material. ChemSusChem 2010, 3, 1227-1235. [CrossRef]

91. John, M.J.; Thomas, S. Biofibres and biocomposites. Carbohydr. Polym. 2008, 71, 343-364. [CrossRef]

92. Liu, Q.; Luo, L.; Zheng, L. Lignins: Biosynthesis and biological functions in plants. Int. J. Mol. Sci. 2018, 19, 335. [CrossRef]

93. Brebu, M.; Vasile, C. Thermal degradation of lignin - A review. Cellul. Chem. Technol. 2010, 44, $353-363$.

94. Ramamoorthy, S.K.; Skrifvars, M.; Persson, A. A review of natural fibers used in biocomposites: Plant, animal and regenerated cellulose fibers. Polym. Rev. 2015, 55, 107-162. [CrossRef]

95. Rozman, H.D.; Tan, K.W.; Kumar, R.N.; Abubakar, A.; Mohd. Ishak, Z.A.; Ismail, H. The effect of lignin as a compatibilizer on the physical properties of coconut fiber-polypropylene composites. Eur. Polym. J. 2000, 36, 1483-1494. [CrossRef]

96. Silva, I.S.; de Menezes, C.R.; Franciscon, E.; dos Santos, E.d.C.; Durrant, L.R. Degradation of lignosulfonic and tannic acids by ligninolytic soil fungi cultivated under icroaerobic conditions. Brazilian Arch. Biol. Technol. 2010, 53, 693-699. [CrossRef]

97. Nurazzi, N.; Khalina, A.; Sapuan, S.; Laila, A.H.D.; Mohamed, R. Curing behaviour of unsaturated polyester resin and interfacial shear stress of sugar palm fibre. J. Mech. Eng. Sci. 2017, 11, 2650-2664. [CrossRef]

98. Norizan, M.N.; Abdan, K.; Salit, M.S.; Mohamed, R. Physical, mechanical and thermal properties of sugar palm yarn fibre loading on reinforced unsaturated polyester composites. J. Phys. Sci. 2017, 28, 115-136. [CrossRef]

99. Haghdan, S.; Renneckar, S.; Smith, G.D. Sources of Lignin. In Lignin in Polymer Composites; William Andrew: Norwich, NY, USA, 2016; pp. 1-11. ISBN 9780323355667.

100. Azeez, M.A.; Orege, J.I. Bamboo, Its Chemical Modification and Products. In Bamboo—Current and Future Prospects; Abdul Khalil, H.P.S., Ed.; InTech: London, UK, 2018.

101. Ansell, M.P.; Mwaikambo, L.Y. The structure of cotton and other plant fibres. In Handbook of Textile Fibre Structure; Elsevier: Amsterdam, The Netherlands, 2009; pp. 62-94. 
102. Barreto, A.C.H.; Rosa, D.S.; Fechine, P.B.A.; Mazzetto, S.E. Properties of sisal fibers treated by alkali solution and their application into cardanol-based biocomposites. Compos. Part A Appl. Sci. Manuf. 2011, 42, 492-500. [CrossRef]

103. Daud, Z.; Mohd Hatta, M.Z.; Mohd Kassi, A.S.; Mohd Aripi, A. Analysis of the Chemical Compositions and Fiber Morphology of Pineapple (Ananas comosus) Leaves in Malaysia. J. Appl. Sci. 2014, 14, 1355-1358. [CrossRef]

104. Zainudin, E.S.; Yan, L.H.; Haniffah, W.H.; Jawaid, M.; Alothman, O.Y. Effect of coir fiber loading on mechanical and morphological properties of oil palm fibers reinforced polypropylene composites. Polym. Compos. 2014, 35, 1418-1425. [CrossRef]

105. Agubra, V.; Owuor, P.; Hosur, M. Influence of Nanoclay Dispersion Methods on the Mechanical Behavior of E-Glass/Epoxy Nanocomposites. Nanomaterials 2013, 3, 550-563. [CrossRef] [PubMed]

106. Li, H.; Huang, X.; Huang, C.; Zhao, Y. An investigation about solid equal channel angular extrusion on polypropylene/organic montmorillonite composite. J. Appl. Polym. Sci. 2012, 123, 2222-2227. [CrossRef]

107. Creasy, T.S.; Kang, Y.S. Fibre fracture during equal-channel angular extrusion of short fibre-reinforced thermoplastics. J. Mater. Process. Technol. 2005, 160, 90-98. [CrossRef]

108. Beloshenko, V.A.; Voznyak, A.V.; Voznyak, Y.V.; Novokshonova, L.A.; Grinyov, V.G.; Krasheninnikov, V.G. Processing of Polypropylene-Organic Montmorillonite Nanocomposite by Equal Channel Multiangular Extrusion. Int. J. Polym. Sci. 2016, 2016, 8564245. [CrossRef]

109. Guo, F.; Aryana, S.; Han, Y.; Jiao, Y. A review of the synthesis and applications of polymer-nanoclay composites. Appl. Sci. 2018, 8, 1696. [CrossRef]

110. Alexandre, M.; Dubois, P. Polymer-layered silicate nanocomposites: Preparation, properties and uses of a new class of materials. Mater. Sci. Eng. R Rep. 2000, 28, 1-63. [CrossRef]

111. Ayana, B.; Suin, S.; Khatua, B.B. Highly exfoliated eco-friendly thermoplastic starch (TPS)/poly (lactic acid)(PLA)/clay nanocomposites using unmodified nanoclay. Carbohydr. Polym. 2014, 110, 430-439. [CrossRef]

112. Tian, H.; Wang, K.; Liu, D.; Yan, J.; Xiang, A.; Rajulu, A.V. Enhanced mechanical and thermal properties of poly (vinyl alcohol)/corn starch blends by nanoclay intercalation. Int. J. Biol. Macromol. 2017, 101, 314-320. [CrossRef]

113. Trifol, J.; Plackett, D.; Sillard, C.; Szabo, P.; Daugaard, A.E. Hybrid poly (lactic acid)/nanocellulose/nanoclay composites with synergistically enhanced barrier properties and improved thermomechanical resistance. Polym. Int. 2016, 65, 988-995. [CrossRef]

114. Li, J.; Zhou, M.; Cheng, G.; Cheng, F.; Lin, Y.; Zhu, P.X. Fabrication and characterization of starch-based nanocomposites reinforced with montmorillonite and cellulose nanofibers. Carbohydr. Polym. 2019, 210, 429-436. [CrossRef]

115. Boonprasith, P.; Wootthikanokkhan, J.; Nimitsiriwat, N. Mechanical, thermal, and barrier properties of nanocomposites based on poly(butylene succinate)/thermoplastic starch blends containing different types of clay. J. Appl. Polym. Sci. 2013, 130, 1114-1123. [CrossRef]

116. Zahedi, M.; Pirayesh, H.; Khanjanzadeh, H.; Tabar, M.M. Organo-modified montmorillonite reinforced walnut shell/polypropylene composites. Mater. Des. 2013, 51, 803-809. [CrossRef]

117. Zhao, Y.; Wang, K.; Zhu, F.; Xue, P.; Jia, M. Properties of poly(vinyl chloride)/wood flour/montmorillonite composites: Effects of coupling agents and layered silicate. Polym. Degrad. Stab. 2006, 91, 2874-2883. [CrossRef]

118. Essabir, H.; Raji, M.; Bouhfid, R.; Qaiss, A.E.K. Nanoclay and Natural Fibers Based Hybrid Composites: Mechanical, Morphological, Thermal and Rheological Properties. In Nanoclay Reinforced Polymer Composites; Mohammad, J., Abouel, K.Q., Rachid, B., Eds.; Springer: Berlin/Heidelberg, Germany, 2016; pp. 175-207.

119. Ku, H.; Wang, H.; Pattarachaiyakoop, N.; Trada, M. A review on the tensile properties of natural fiber reinforced polymer composites. Compos. Part B Eng. 2011, 42, 856-873. [CrossRef]

120. Saba, N.; Tahir, P.M.; Jawaid, M. A review on potentiality of nano filler/natural fiber filled polymer hybrid composites. Polymers 2014, 6, 2247-2273. [CrossRef]

121. Yousefian, H.; Rodrigue, D. Hybrid Composite Foams Based on Nanoclays and Natural Fibres. In Nanoclay Reinforced Polymer Composites; Mohammad, J., Abouel, K.Q., Rachid, B., Eds.; Springer: Berlin/Heidelberg, Germany, 2016; pp. $175-207$.

122. Santulli, C. Nanoclay Based Natural Fibre Reinforced Polymer Composites: Mechanical and Thermal Properties. In Nanoclay Reinforced Polymer Composites; Mohammad, J., Abouel, K.Q., Rachid, B., Eds.; Springer: Berlin/Heidelberg, Germany, 2016; pp. 175-207.

123. Nisini, E.; Santulli, C.; Liverani, A. Mechanical and impact characterization of hybrid composite laminates with carbon, basalt and flax fibres. Compos. Part B Eng. 2017, 127, 92-99. [CrossRef]

124. Rozman, H.D.; Rozyanty, A.R.; Musa, L.; Tay, G.S. Ultra-violet radiation-cured biofiber composites from kenaf: The effect of montmorillonite on the flexural and impact properties. J. Wood Chem. Technol. 2010, 30, 152-163. [CrossRef]

125. Hetzer, M.; De Kee, D. Wood/polymer/nanoclay composites, environmentally friendly sustainable technology: A review. Chem. Eng. Res. Des. 2008, 86, 1083-1093. [CrossRef]

126. Chen, Z.; Kuang, T.; Yang, Z.; Ren, X. Effect of Nanoclay on Natural Fiber/Polymer Composites. In Nanoclay Reinforced Polymer Composites; Mohammad, J., Abouel, K.Q., Rachid, B., Eds.; Springer: Berlin/Heidelberg, Germany, 2016; pp. $175-207$.

127. Zahedi, M.; Khanjanzadeh, H.; Pirayesh, H.; Saadatnia, M.A. Utilization of natural montmorillonite modified with dimethyl, dehydrogenated tallow quaternary ammonium salt as reinforcement in almond shell flour-polypropylene bio-nanocomposites. Compos. Part B Eng. 2015, 71, 143-151. [CrossRef]

128. Petersson L, O.K. Biopolymer based nanocomposites: Comparing layered silicates and microcrystalline cellulose as nanoreinforcement. Compos. Sci. Technol. 2006, 66, 2187-2196. [CrossRef] 
129. Arjmandi, R.; Hassan, A.; Haafiz, M.K.M.; Zakaria, Z. Effect of microcrystalline cellulose on biodegradability, tensile and morphological properties of montmorillonite reinforced polylactic acid nanocomposites. Fibers Polym. 2015, 16, $2284-2293$. [CrossRef]

130. Jalalvandi, E.; Majid, R.A.; Ghanbari, T.; Ilbeygi, H. Effects of montmorillonite (MMT) on morphological, tensile, physical barrier properties and biodegradability of polylactic acid/starch/MMT nanocomposites. J. Thermoplast. Compos. Mater. 2015, 28, 496-509. [CrossRef]

131. Saba, N.; Paridah, M.T.; Abdan, K.; Ibrahim, N.A. Effect of oil palm nano filler on mechanical and morphological properties of kenaf reinforced epoxy composites. Constr. Build. Mater. 2016, 123, 15-26. [CrossRef]

132. Thakur, V.K.; Thakur, M.K.; Gupta, R.K. Review: Raw Natural Fiber-Based Polymer Composites. Int. J. Polym. Anal. Charact. 2014, 19, 256-271. [CrossRef]

133. Islam, M.S.; Ahmad, M.B.; Hasan, M.; Aziz, S.A.; Jawaid, M.; Haafiz, M.K.M.; Zakaria, S.A.H. Natural fiber-reinforced hybrid polymer nanocomposites: Effect of fiber mixing and nanoclay on physical, mechanical, and biodegradable properties. BioResources 2015, 10, 1394-1407. [CrossRef]

134. Goodarzi, V.; Jafari, S.H.; Khonakdar, H.A.; Seyfi, J. Morphology, rheology and dynamic mechanical properties of PP/EVA/clay nanocomposites. J. Polym. Res. 2011, 18, 1829-1839. [CrossRef]

135. Mata-Padilla, J.M.; Medellín-Rodríguez, F.J.; Ávila-Orta, C.A.; Ramírez-Vargas, E.; Cadenas-Pliego, G.; Valera-Zaragoza, M.; Vega-Díaz, S.M. Morphology and chain mobility of reactive blend nanocomposites of PP-EVA/Clay. J. Appl. Polym. Sci. 2014, 131, 1-14. [CrossRef]

136. Castro-Landinez, J.F.; Salcedo-Galan, F.; Medina-Perilla, J.A. Polypropylene/ethylene-and polar-monomer-based copolymers/montmorillonite nanocomposites: Morphology, mechanical properties, and oxygen permeability. Polymers 2021, 13, 705. [CrossRef]

137. Shikaleska, A.V.; Pavlovska, F.P. Advanced materials based on polymer blends/polymer blend nanocomposites. IOP Conf. Ser. Mater. Sci. Eng. 2012, 40, 012009. [CrossRef]

138. Sengwa, R.J.; Choudhary, S. Structural characterization of hydrophilic polymer blends/montmorillonite clay nanocomposites. J. Appl. Polym. Sci. 2014, 131, 1-11. [CrossRef]

139. Ramesh, P.; Prasad, B.D.; Narayana, K.L. Influence of Montmorillonite Clay Content on Thermal, Mechanical, Water Absorption and Biodegradability Properties of Treated Kenaf Fiber/ PLA-Hybrid Biocomposites. Silicon 2021, 13, 109-118. [CrossRef]

140. Gwon, J.G.; Lee, S.Y.; Chun, S.J.; Doh, G.H.; Kim, J.H. Physical and mechanical properties of wood-plastic composites hybridized with inorganic fillers. J. Compos. Mater. 2012, 46, 301-309. [CrossRef]

141. Khare, A.; Deshmukh, S. Studies Toward Producing Eco-Friendly Plastics. J. Plast. Film Sheeting 2006, 22, 193-211. [CrossRef]

142. Tajeddin, B.; Rahman, R.A.; Abdulah, L.C. The effect of polyethylene glycol on the characteristics of kenaf cellulose/low-density polyethylene biocomposites. Int. J. Biol. Macromol. 2010, 47, 292-297. [CrossRef]

143. George, J.; Kumar, R.; Jayaprahash, C.; Ramakrishna, A.; Sabapathy, S.N.; Bawa, A.S. Rice bran-filled biodegradable low-density polyethylene films: Development and characterization for packaging applications. J. Appl. Polym. Sci. 2006, 102, 4514-4522. [CrossRef]

144. Kalia, S.; Kaith, B.S.; Kaur, I. Pretreatments of Natural Fibers and their Application as Reinforcing Material in Polymer Composites - A Review. Polym. Eng. Sci. 2009, 49, 1253-1272. [CrossRef]

145. Majeed, K.; Jawaid, M.; Hassan, A.; Abu Bakar, A.; Abdul Khalil, H.P.S.; Salema, A.A.; Inuwa, I. Potential materials for food packaging from nanoclay/natural fibres filled hybrid composites. Mater. Des. 2013, 46, 391-410. [CrossRef]

146. Chee, S.S.; Jawaid, M.; Alothman, O.Y.; Fouad, H. Effects of nanoclay on mechanical and dynamic mechanical properties of bamboo/kenaf reinforced epoxy hybrid composites. Polymers 2021, 13, 395. [CrossRef]

147. Wei, J.; Wang, B.; Li, Z.; Wu, Z.; Zhang, M.; Sheng, N.; Liang, Q.; Wang, H.; Chen, S. A 3D-printable TEMPO-oxidized bacterial cellulose/alginate hydrogel with enhanced stability via nanoclay incorporation. Carbohydr. Polym. 2020, 238, 116207. [CrossRef]

148. Mohan, T.P.; Kanny, K. Compressive characteristics of unmodified and nanoclay treated banana fiber reinforced epoxy composite cylinders. Compos. Part B Eng. 2019, 169, 118-125. [CrossRef]

149. Chee, S.S.; Jawaid, M.; Sultan, M.T.H.; Alothman, O.Y.; Abdullah, L.C. Thermomechanical and dynamic mechanical properties of bamboo/woven kenaf mat reinforced epoxy hybrid composites. Compos. Part B Eng. 2019, 163, 165-174. [CrossRef]

150. Anand, G.; Alagumurthi, N.; Elansezhian, R.; Venkateshwaran, N. Dynamic mechanical, thermal and wear analysis of Ni-P coated glass fiber $/ \mathrm{Al}_{2} \mathrm{O}_{3}$ nanowire reinforced vinyl ester composite. Alexandria Eng. J. 2018, 57, 621-631. [CrossRef]

151. Joseph, S.; Appukuttan, S.P.; Kenny, J.M.; Puglia, D.; Thomas, S.; Joseph, K. Dynamic mechanical properties of oil palm microfibril-reinforced natural rubber composites. J. Appl. Polym. Sci. 2010, 117, 1298-1308. [CrossRef]

152. Majeed, K.; Hassan, A.; Bakar, A.A. Influence of maleic anhydride-grafted polyethylene compatibiliser on the tensile, oxygen barrier and thermal properties of rice husk and nanoclay-filled low-density polyethylene composite films. J. Plast. Film Sheeting 2014, 30, 120-140. [CrossRef]

153. Ali Dadfar, S.M.; Alemzadeh, I.; Reza Dadfar, S.M.; Vosoughi, M. Studies on the oxygen barrier and mechanical properties of low density polyethylene/organoclay nanocomposite films in the presence of ethylene vinyl acetate copolymer as a new type of compatibilizer. Mater. Des. 2011, 32, 1806-1813. [CrossRef]

154. Arulmurugan, S.; Venkateshwaran, N. Effect of nanoclay addition and chemical treatment on static and dynamic mechanical analysis of jute fibre composites. Polímeros 2019, 29, 4-11. [CrossRef] 
155. Palanivel, A.; Veerabathiran, A.; Duruvasalu, R.; Iyyanar, S.; Velumayil, R. Dynamic mechanical analysis and crystalline analysis of hemp fiber reinforced cellulose filled epoxy composite. Polímeros 2017, 27, 309-319. [CrossRef]

156. Jesuarockiam, N.; Jawaid, M.; Zainudin, E.S.; Hameed Sultan, M.T.; Yahaya, R. Enhanced thermal and dynamic mechanical properties of synthetic/natural hybrid composites with graphene nanoplateletes. Polymers 2019, 11, 1085. [CrossRef] [PubMed]

157. Yussuf, A.A.; Massoumi, I.; Hassan, A. Comparison of Polylactic Acid/Kenaf and Polylactic Acid/Rise Husk Composites: The Influence of the Natural Fibers on the Mechanical, Thermal and Biodegradability Properties. J. Polym. Environ. 2010, 18, 422-429. [CrossRef]

158. Ilyas, R.A.; Sapuan, S.M.; Ibrahim, R.; Abral, H.; Ishak, M.R.; Zainudin, E.S.; Asrofi, M.; Atikah, M.S.N.; Huzaifah, M.R.M.; Radzi, A.M.; et al. Sugar palm (Arenga pinnata (Wurmb.) Merr) cellulosic fibre hierarchy: A comprehensive approach from macro to nano scale. J. Mater. Res. Technol. 2019, 8, 2753-2766. [CrossRef]

159. Ilyas, R.A.; Sapuan, S.M.; Ishak, M.R. Isolation and characterization of nanocrystalline cellulose from sugar palm fibres (Arenga pinnata). Carbohydr. Polym. 2018, 181, 1038-1051. [CrossRef]

160. Ilyas, R.A.; Sapuan, S.M.; Ishak, M.R.; Zainudin, E.S. Sugar palm nanofibrillated cellulose (Arenga pinnata (Wurmb.) Merr): Effect of cycles on their yield, physic-chemical, morphological and thermal behavior. Int. J. Biol. Macromol. 2019, 123, 379-388. [CrossRef]

161. Ilyas, R.A.; Sapuan, S.M.; Ishak, M.R.; Zainudin, E.S. Effect of delignification on the physical, thermal, chemical, and structural properties of sugar palm fibre. BioResources 2017, 12, 8734-8754. [CrossRef]

162. Ayu, R.S.; Khalina, A.; Harmaen, A.S.; Zaman, K.; Isma, T.; Liu, Q.; Ilyas, R.A.; Lee, C.H. Characterization Study of Empty Fruit Bunch (EFB) Fibers Reinforcement in Poly(Butylene) Succinate (PBS)/Starch/Glycerol Composite Sheet. Polymers 2020, $12,1571$. [CrossRef]

163. Syafri, E.; Sudirman; Mashadi; Yulianti, E.; Deswita; Asrofi, M.; Abral, H.; Sapuan, S.M.; Ilyas, R.A.; Fudholi, A. Effect of sonication time on the thermal stability, moisture absorption, and biodegradation of water hyacinth (Eichhornia crassipes) nanocellulose-filled bengkuang (Pachyrhizus erosus) starch biocomposites. J. Mater. Res. Technol. 2019, 8, 6223-6231. [CrossRef]

164. Ismail, H.; Pasbakhsh, P.; Fauzi, M.N.A.; Abu Bakar, A. Morphological, thermal and tensile properties of halloysite nanotubes filled ethylene propylene diene monomer (EPDM) nanocomposites. Polym. Test. 2008, 27, 841-850. [CrossRef]

165. Sajna, V.; Mohanty, S.; Nayak, S.K. Hybrid green nanocomposites of poly(lactic acid) reinforced with banana fibre and nanoclay. J. Reinf. Plast. Compos. 2014, 33, 1717-1732. [CrossRef]

166. Huda, M.S.; Drzal, L.T.; Mohanty, A.K.; Misra, M. Effect of fiber surface-treatments on the properties of laminated biocomposites from poly(lactic acid) (PLA) and kenaf fibers. Compos. Sci. Technol. 2008, 68, 424-432. [CrossRef]

167. Du, Y.; Wu, T.; Yan, N.; Kortschot, M.T.; Farnood, R. Fabrication and characterization of fully biodegradable natural fiberreinforced poly(lactic acid) composites. Compos. Part B Eng. 2014, 56, 717-723. [CrossRef]

168. Yuzay, I.E.; Auras, R.; Soto-Valdez, H.; Selke, S. Effects of synthetic and natural zeolites on morphology and thermal degradation of poly(lactic acid) composites. Polym. Degrad. Stab. 2010, 95, 1769-1777. [CrossRef]

169. Mróz, P.; Białas, S.; Mucha, M.; Kaczmarek, H. Thermogravimetric and DSC testing of poly(lactic acid) nanocomposites. Thermochim. Acta 2013, 573, 186-192. [CrossRef]

170. Pratheep Kumar, A.; Pal Singh, R. Novel hybrid of clay, cellulose, and thermoplastics. I. Preparation and characterization of composites of ethylene-propylene copolymer. J. Appl. Polym. Sci. 2007, 104, 2672-2682. [CrossRef]

171. Blumstein, A. Polymerization of adsorbed monolayers. II. Thermal degradation of the inserted polymer. J. Polym. Sci. Part A Gen. Pap. 1965, 3, 2665-2672. [CrossRef]

172. Burnside, S.D.; Giannelis, E.P. Synthesis and properties of new poly(dimethylsiloxane) nanocomposites. Chem. Mater. 1995, 7, 1597-1600. [CrossRef]

173. Tyan, H.-L.; Liu, Y.-C.; Wei, K.-H. Thermally and Mechanically Enhanced Clay/Polyimide Nanocomposite via Reactive Organoclay. Chem. Mater. 1999, 11, 1942-1947. [CrossRef]

174. Amash, A. Morphology and properties of isotropic and oriented samples of cellulose fibre-polypropylene composites. Polymer 2000, 41, 1589-1596. [CrossRef]

175. Bharadwaj, R.K.; Mehrabi, A.R.; Hamilton, C.; Trujillo, C.; Murga, M.; Fan, R.; Chavira, A.; Thompson, A.K. Structure-property relationships in cross-linked polyester-clay nanocomposites. Polymer 2002, 43, 3699-3705. [CrossRef]

176. Tidjani, A.; Wald, O.; Pohl, M.-M.; Hentschel, M.P.; Schartel, B. Polypropylene-graft-maleic anhydride-nanocomposites: ICharacterization and thermal stability of nanocomposites produced under nitrogen and in air. Polym. Degrad. Stab. 2003, 82, 133-140. [CrossRef]

177. Ohkita, T.; Lee, S.-H. Thermal degradation and biodegradability of poly (lactic acid)/corn starch biocomposites. J. Appl. Polym. Sci. 2006, 100, 3009-3017. [CrossRef]

178. Jumaidin, R.; Diah, N.A.; Ilyas, R.A.; Alamjuri, R.H.; Yusof, F.A.M. Processing and Characterisation of Banana Leaf Fibre Reinforced Thermoplastic Cassava Starch Composites. Polymers 2021, 13, 1420. [CrossRef]

179. Jumaidin, R.; Khiruddin, M.A.A.; Asyul Sutan Saidi, Z.; Salit, M.S.; Ilyas, R.A. Effect of cogon grass fibre on the thermal, mechanical and biodegradation properties of thermoplastic cassava starch biocomposite. Int. J. Biol. Macromol. 2020, 146, 746-755. [CrossRef]

180. Threepopnatkul, P.; Kaerkitcha, N.; Athipongarporn, N. Effect of surface treatment on performance of pineapple leaf fiberpolycarbonate composites. Compos. Part B Eng. 2009, 40, 628-632. [CrossRef] 
181. Mofokeng, J.P.; Luyt, A.S.; Tábi, T.; Kovács, J. Comparison of injection moulded, natural fibre-reinforced composites with PP and PLA as matrices. J. Thermoplast. Compos. Mater. 2012, 25, 927-948. [CrossRef]

182. Ahmed, A.; Hidayat, S.; Abu Bakar, M.S.; Azad, A.K.; Sukri, R.S.; Phusunti, N. Thermochemical characterisation of Acacia auriculiformis tree parts via proximate, ultimate, TGA, DTG, calorific value and FTIR spectroscopy analyses to evaluate their potential as a biofuel resource. Biofuels 2021, 12, 9-20. [CrossRef]

183. Majeed, K.; Hassan, A.; Bakar, A.A.; Jawaid, M. Effect of montmorillonite (MMT) content on the mechanical, oxygen barrier, and thermal properties of rice husk/MMT hybrid filler-filled low-density polyethylene nanocomposite blown films. J. Thermoplast. Compos. Mater. 2016, 29, 1003-1019. [CrossRef]

184. Bertini, F.; Canetti, M.; Audisio, G.; Costa, G.; Falqui, L. Characterization and thermal degradation of polypropylenemontmorillonite nanocomposites. Polym. Degrad. Stab. 2006, 91, 600-605. [CrossRef]

185. Leszczyńska, A.; Njuguna, J.; Pielichowski, K.; Banerjee, J.R. Polymer/montmorillonite nanocomposites with improved thermal properties. Part, I. Factors influencing thermal stability and mechanisms of thermal stability improvement. Thermochim. Acta 2007, 453, 75-96. [CrossRef]

186. Chow, W.S.; Mohd Ishak, Z.A.; Karger-Kocsis, J.; Apostolov, A.A.; Ishiaku, U.S. Compatibilizing effect of maleated polypropylene on the mechanical properties and morphology of injection molded polyamide 6/polypropylene/organoclay nanocomposites. Polymer 2003, 44, 7427-7440. [CrossRef]

187. Zaman, H.U.; Hun, P.D.; Khan, R.A.; Yoon, K.-B. Polypropylene/clay nanocomposites. J. Thermoplast. Compos. Mater. 2014, 27, 338-349. [CrossRef]

188. Rajini, N.; Winowlin Jappes, J.T.; Rajakarunakaran, C.; Siva, I. Tensile and Flexural Properties of MMT-Clay/ Unsaturated Polyester Using Robust Design Concept. Nano Hybrids 2012, 2, 87-101. [CrossRef]

189. Sienkiewicz, A.; Czub, P. Flame retardancy of biobased composites—research development. Materials 2020, 13, 5253. [CrossRef]

190. Suwanniroj, A.; Suppakarn, N. Enhancement of flame retardancy and mechanical properties of poly(butylene succinate) composites by adding hybrid fillers. AIP Conf. Proc. 2020, 2279, 070004. [CrossRef]

191. Subasinghe, A.; Das, R.; Bhattacharyya, D. Study of thermal, flammability and mechanical properties of intumescent flame retardant PP/kenaf nanocomposites. Int. J. Smart Nano Mater. 2016, 7, 202-220. [CrossRef]

192. Chee, S.S.; Jawaid, M.; Alothman, O.Y.; Yahaya, R. Thermo-oxidative stability and flammability properties of bamboo/kenaf/nanoclay/epoxy hybrid nanocomposites. RSC Adv. 2020, 10, 21686-21697. [CrossRef]

193. Dutta, N.; Maji, T.K. Synergic effect of montmorillonite and microcrystalline cellulose on the physicochemical properties of rice husk/PVC composite. SN Appl. Sci. 2020, 2, 439. [CrossRef]

194. Wang, Y.Y.; Shih, Y.F. Flame-retardant recycled bamboo chopstick fiber-reinforced poly(lactic acid) green composites via multifunctional additive system. J. Taiwan Inst. Chem. Eng. 2016, 65, 452-458. [CrossRef]

195. Mandal, M.; Halim, Z.; Maji, T.K. Mechanical, moisture absorption, biodegradation and physical properties of nanoclay-reinforced wood/plant oil composites. SN Appl. Sci. 2020, 2, 250. [CrossRef]

196. Glaskova-Kuzmina, T.; Starkova, O.; Gaidukovs, S.; Platnieks, O.; Gaidukova, G. Durability of Biodegradable Polymer Nanocomposites. Polymers 2021, 13, 3375. [CrossRef]

197. Islam, M.S.; Hasbullah, N.A.B.; Hasan, M.; Talib, Z.A.; Jawaid, M.; Haafiz, M.K.M. Physical, mechanical and biodegradable properties of kenaf/coir hybrid fiber reinforced polymer nanocomposites. Mater. Today Commun. 2015, 4, 69-76. [CrossRef]

198. Kumar, S.; Krishnan, S.; Samal, S.K. Recent Developments of Epoxy Nanocomposites Used for Aerospace and Automotive Application. In Diverse Applications of Organic-Inorganic Nanocomposites: Emerging Research and Opportunities; Clarizia, G., Bernardo, P., Eds.; IGI Global: Pittsburgh, PA, USA, 2020; pp. 162-190.

199. Galimberti, M.; Cipolletti, V.R.; Coombs, M. Applications of clay-polymer nanocomposites. In Developments in Clay Science; Elsevier: Amsterdam, The Netherlands, 2013; pp. 539-586.

200. Lyon, R.E.; Walters, R.N. Flammability of automotive plastics. SAE Tech. Pap. 2006. [CrossRef]

201. Jiang, R.; Michaels, H.; Vlachopoulos, N.; Freitag, M. Beyond the Limitations of Dye-Sensitized Solar Cells. In Dye-Sensitized Solar Cells: Mathematical Modeling, and Materials Design and Optimization; Soroush, M., Lau, K.K.S., Eds.; Academic Press: Cambridge, UK, 2019; pp. 285-323.

202. Beg, M.D.H.; Pickering, K.L. Accelerated weathering of unbleached and bleached Kraft wood fibre reinforced polypropylene composites. Polym. Degrad. Stab. 2008, 93, 1939-1946. [CrossRef]

203. Searle, N.D.; McGreer, M.; Zielnik, A. Weathering of Polymeric Materials. In Encyclopedia of Polymer Science and Technology; Matyjaszewski, K., Ed.; John Wiley \& Sons, Inc.: Hoboken, NJ, USA, 2010.

204. Brown, R.P.; Kockott, D.; Trubiroha, P.; Ketola, W.; Shorthouse, J. A Review of Accelerated Durability Tests; National Physical Laboratory Teddington: Middlesex, UK, 1995.

205. Raji, M.; Zari, N.; Bouhfid, R.; el kacem Qaiss, A. Durability of composite materials during hydrothermal and environmental aging. In Durability and Life Prediction in Biocomposites, Fibre-Reinforced Composites and Hybrid Composites; Jawaid, M., Thariq, M., Saba, N., Eds.; Woodhead Publishing Series: Cambridge, UK, 2019; pp. 83-119.

206. Kord, B.; Malekian, B.; Ayrilmis, N. Weathering Performance of Montmorillonite/Wood Flour-Based Polypropylene Nanocomposites. Mech. Compos. Mater. 2017, 53, 271-278. [CrossRef]

207. Eshraghi, A.; Khademieslam, H.; Ghasemi, I.; Talaiepoor, M. Effect of weathering on the properties of hybrid composite based on polyethylene, woodflour, and nanoclay. BioResources 2013, 8, 201-210. [CrossRef] 
208. High Efficiency Plants and Building Integrated Renewable Energy Systems. In Handbook of Energy Efficiency in Buildings: A Life Cycle Approach; Asdrubali, F.; Desideri, U. (Eds.) Butterworth-Heinemann: Oxford, UK, 2019; pp. 441-595.

209. Nguyen, Q.; Ngo, T.; Mendis, P.; Tran, P. Composite Materials for Next Generation Building Façade Systems. Civ. Eng. Archit. 2013, 1, 88-95. [CrossRef]

210. Nguyen, Q.T.; Tran, P.; Ngo, T.D.; Tran, P.A.; Mendis, P. Experimental and computational investigations on fire resistance of GFRP composite for building façade. Compos. Part B Eng. 2014, 62, 218-229. [CrossRef]

211. Rajini, N.; Winowlin Jappes, J.T.; Siva, I.; Varada Rajulu, A.; Rajakarunakaran, S. Fire and thermal resistance properties of chemically treated ligno-cellulosic coconut fabric-reinforced polymer eco-nanocomposites. J. Ind. Text. 2017, 47, 104-124. [CrossRef]

212. Chowdhury, S.R. Some important aspects in designing high molecular weight poly(L-lactic acid)-clay nanocomposites with desired properties. Polym. Int. 2008, 57, 1326-1332. [CrossRef]

213. Mohan, T.P.; Kanny, K. Sorption studies of few selected raw and nanoclay infused lignocellulosic fibres. Indian J. Fibre Text. Res. 2019, 44, 263-270.

214. Massaro, M.; Cavallaro, G.; Lazzara, G.; Riela, S. Covalently modified nanoclays: Synthesis, properties and applications. In Clay Nanoparticles: Properties and Applications; Cavallaro, G., Fakhrullin, R., Pasbakhsh, P., Eds.; Elsevier: Amsterdam, The Netherlands, 2020; pp. 305-333.

215. Maisanaba, S.; Hercog, K.; Filipic, M.; Jos, Á.; Zegura, B. Genotoxic potential of montmorillonite clay mineral and alteration in the expression of genes involved in toxicity mechanisms in the human hepatoma cell line HepG2. J. Hazard. Mater. 2016, 304, 425-433. [CrossRef]

216. Shafique, M.; Luo, X. Nanotechnology in Transportation Vehicles: An Overview of Its Applications, Environmental, Health and Safety Concerns. Materials 2019, 12, 2493. [CrossRef] 